EstAg 32 (1997) 171-216

\title{
El Jesús histórico y el Jesus seminar
}

La investigación de la historia de Jesús está probablemente más viva que nunca. Se habla con razón que se ha entrado definitivamente en la Third Quest. Ha quedado atrás la Old Quest del s. XIX "la hazaña más grandiosa de la teología alemana" estudiada por A. Schweitzer ${ }^{1}$. También se ha dicho adiós, al menos en ambientes americanos e ingleses, a la New Quest así denominada por J. M. Robinson ${ }^{2}$, que arranca en los años $50^{3}$. A partir de los años 70 y 80 puede afirmarse que el Jesús histórico es estudiado en amplios círculos de un manera nueva.

¿Cuáles son las causas que han provocado este cambio y este renacimiento del interés por el Jesús histórico? Ciertamente no ha habido descubrimiento de documentos nuevos. Bajo este punto de vista lo único que se puede decir es que la novedad ha consistido en la revalorización y mayor aprecio de fuentes ya conocidas anteriormente, especialmente del famoso Evangelio de Tomás.

Tampoco los métodos han cambiado especialmente, si bien ahora se presta mayor atención a las ciencias sociales y a la arqueología para recomponer el mundo en que Jesús vivió.

Sin duda lo que más ha cambiado son los presupuestos de que parte el historiador y el espíritu y mentalidad con que ejerce su trabajo. En todo caso parece más que justificado hablar con justicia de una Third Quest ${ }^{4}$.

1. A. SCHWEITZER, Investigaciones sobre la vida de Jesís. Valencia 1990, 24.

2. ÇA New Quest of the Historical Jesus. 1959, 26.

3. Suele fijarse el comienzo de la New Quest en la conferencia dada por E. Käsemann a los antiguos alumnos de Marburg en 1953. Esta conferencia fue publicada en Zeit. f. Theol. u. Kirche 51(1954)125-153; luego recogida en E. KÄSEMANN, E., Ensayos Exegéticos. Salamanca 1978, 159-189.=

4. Es ya una denominación general. N. T. WRIGHT-S. C. NEILL, The Interpretation of the New Testament 1861-1986. Oxford 1988, 379-403; la aprueban M. J. BORG, "Reflections on a Discipline: A North American Perspective": B. CHILTON \& C. A. EVANS (Ed.), Studying the Historical Jesus: Evaluations of the State of Current Research. Leiden 1994, 9-31, espec. 17; G. THEISSEN- A. MERZ, Der Historische Jesus. Ein Lehrbuch. Göttingen 1996,28-29; entra a forma parte del subtitulo del libro de B. WITHERINGTON III, The Jesus Quest. The Third Search for the Jew of Nazareth. Downers Grove, Il. 1995. G. Theissen, que acoge la denominación de "Third Quest" en la obra citada, distingue cinco fases en la investigación: la $1^{\mathrm{a}}$ que discurrre desde Reimarus hasta D. F. Strauss; la $2^{\mathrm{a}}$ es la época de la crítica 


\section{La Third Quest}

He aquí las diferencias que separan las dos últimas etapas de la investigación 5 .

1) La New Quest nace impregnada de teología e incluso de apologética. Resulta instructivo leer hoy la conferencia de E. Käseman de 1953, en la que él se ve obligado a justificar teológicamente la búsqueda del Jesús histórico. La razón que daba era que aceptar el kerigma lleva consigo aceptar la figura de Jesús de Nazaret: “(No) es posible captar adecuadamente el significado de Pascua si se prescinde del Jesús terreno"6. A la distancia en que estamos y tras el declive de la teología de Bultmann resulta realmente chocante que alguna vez se haya tenido que luchar para defender que un cristiano pueda tener interés por lo que Jesús de Nazaret hizo y dijo.

Naturalmente los promotores de la Third Quest consideran inaceptable que la teología pueda poner reparos a la investigación histórica. Lo consideran una intromisión y una confusión de métodos. Si Jesús es una persona histórica debe ser investigada de una manera puramente histórica.

Ha habido una evidente secularización de la investigación. Antes señalábamos que, a nuestro juicio, lo que distingue a la Third Quest de la New Quest es la mentalidad y los presupuestos del historiador. Con ello nos referimos al hecho de que la religión se estudia como fenómeno cultural en los Departamentos de Estudios Religiosos de las Universidades plenamente secularizados. Ya hace años T. L. Thompson ${ }^{7}$ constataba y se felicitaba del acceso a los estudios bíblicos de generaciones jóvenes instaladas en las facultades de religión pertenecientes a la universidades estatales, que estudian el pasado con la mentalidad de anticuario sin preocupación teológica alguna. Antes, es cierto, en Alemania y en el mundo anglosajón ya había seglares que se dedicaban a estos estudios, pero lo hacían profundamente imbuidos de una intensa formación religiosa y en la mayor parte de los casos bajo una cierta

liberal del s. XIX; Bultmann ocupa la $3^{\text {a }}$; la New Quest es la $4^{\text {a }}$ y finalmente la $5^{\text {a }}$ fase que discurre desde los años 80 comprende la Third Quest. Las dos primeras fases en sus objetivos y presupuestos apenas se distinguen; la épóca bultmaniana desde luego no puede llamarse "quest", pues consideró la investigación de la historia de Jesús como críticamente imposible y teológicamente inaceptable.

5. Sobre las características singulares de la Third Quest véase, B. F. MEYER, The Aims of Jesus. London 1979, 16-20; J. H. CHARLESWORTH, Jesus Within Judaism. New York 1988, 26-28; N. T. WRIGHT- S. C. NEILL, The Interpretation of the New Testament 1861-1986. Oxford 1988, 397-398.

6. Ensayos, 169.

7. The Origin Tradition of Ancient Israel. I. The Literary Formation of Genesis and Exodus 1-23. Sheffield 1987.11-15. 
tutela de las iglesias. De un modo o de otro buscaban razones para su fe y creencias. Y el proceder era el mismo tanto del Alttestamentler como del Neutestamentler. En la investigación del A. T. se concentraban en la singularidad única y especial de Israel y de su fe; la credibilidad, fiabilidad y verosimilitud de la tradiciones eran buscadas con cariño porque los estudiosos aceptaban en su mayor parte la fe de que Dios se había manifestado a través de la historia. De esta manera certificar la antigüedad de las tradiciones era percibir de alguna manera la manifestación divina. El especialista del N. T. partía también de la singularidad extraordinaria de Jesús de Nazaret y en el fondo de un modo o de otro hacía una labor de apologeta, bien como Bultmann porque la investigación perjudicaba a la fe, o bien como la mayoría porque el estudio de Jesús enriquecía la vivencia religiosa. Ahora, en cambio, el nuevo estudioso tanto del A. como del N.T. prescinde de la fe en su quehacer histórico. Quiere ser más aséptico, al menos aparentemente; no se verá libre de prejuicios, pues es imposible, pero será muy remiso a la hora de establecer un lazo de unión entre la tradición y el suceso, y más aún entre éste y su carácter revelador.

Las dos previas fases eran teológicas. La Old Quest en el sentido de que era antidogmática, la New Quest conscientemente era teológica, buscando los lazos de continuidad entre el Jesús histórico y el kerigma eclesial. La Third Quest unánimemente proclama su separación de cualquier tarea teológica, aunque en diferentes formas.

2) Fuertemente influenciada por intereses teológicos no podía por menos la New Quest de acentuar la singularidad de Jesús frente al judaísmo y frente a la comunidad cristiana. Así lo formulaba E. Käsemann "en cierto modo no tenemos suelo seguro bajo nuestros pies más que en un solo caso: cuando una tradición, por motivos de cualquier género, no puede deducirse del judaísmo ni atribuirse a la cristiandad primitiva"8. Este es el criterio de desemejanza o discontinuidad que es considerado como la piedra filosofal para averiguar lo más genuino, singular y seguro de Jesús. Se era consciente de que tal criterio presenta problemas; por ejemplo el criterio supone que se conozca bien el judaísmo anterior a los años 70 a. C., lo que evidentemente es mucho pedir; el criterio requiere también que se conozcan las tendencias del cristianismo primitivo; en realidad sabemos bastante de la cristiandad pagano-cristiana, mientras que de la comunidad judeo-cristiana los conocimientos son muy escasos.

8. Ensayos, 179. 
Se era consciente también de que el criterio tiene otra debilidad. ¿Cómo Jesús y el judaísmo no iban a tener muchas ideas en común?. La mayor parte de los hombres de una época las tienen. El criterio desecha totalmente este campo. De otra parte el cristianismo sin duda guardó en su doctrina y en su práctica muchas cosas de Jesús; se considera seguidora y continuadora del maestro. Es también otro campo desechado por el criterio.

De todo esto resultaba que el Jesús averiguado por este criterio es en realidad un fantasma, un Jesús irreal. Es claro que "el Jesús histórico" no debe confundirse con el "Jesús real", es decir, con el "Jesús tal cual fue". El Jesús histórico "es una construcción histórica, una abstracción teórica de los estudiosos de hoy que coincide sólo parcialmente con el Jesús real"10. Quizá la ciencia histórica no pueda hacer otra cosa más que buscar un Jesús fantasma, pero metodológicamente no es de recibo presentar como básico y fundamental un criterio que por principio nos va a poner delante un Jesús que como tal no existió.

Esta primacía dada al criterio de discontinuidad es inaceptable para la Third Quest. Esta corriente no está centrada en establecer la autenticidad de ésta o aquella perícopa, sino alcanzar a Jesús de manera más amplia en su ambiente. ¿Qué importancia puede tener establecer la autenticidad de ésta o aquella palabra? ¿Qué certeza puede alcanzarse sobre ciertas palabras concretas?. No mucha, responden los partidarios de la Third Quest. La no derivabilidad de una doctrina no es verificable, pues no poseemos todas las fuentes, sino solamente una selección"1. De hecho la práctica del criterio por los estudiosos llevaba a diferentes resultados.

3) La ambientación de Jesús en el medio judío es otra característica de la Third Quest. Mientras que la New Quest desligaba a Jesús del judaísmo, ésta otra advierte que una persona histórica solamente en su contexto histórico es accesible y sólo es cognoscible a través de los testimonios que de su actuación se conserven. Jesús intentó restaurar el judaísmo; el cristianismo fue en origen un movimiento interno judío; prueba de ello es la elección de los doce. Por tanto hay que sorprender la singularidad de Jesús dentro del judaísmo con el que tiene que tener muchas cosas en común.

4) Debido a ello es propio de la Third Quest un estudio interdisciplinar. Se prima especialmente el uso de la antropología cultural y de la sociología.

9. Ch. E. CARLSTON, "Prologue" : B. CHILTON- C. E. EVANS (Eds), Studying the Historical Jesus, 2-3.

10. J. P. MEIER, A Marginal Jew. Vol. II. New York 1994, 4-5.

11. G. THEISSEN- A. MERZ, Der Historische Jesus, 117. 
Movimientos milenaristas suscitados en torno a la figura de un profeta hubo en tiempo de Jesús y también en otras culturas. Es sabido que la sociología se fija en lo genérico de un movimiento social que manifiesta sus intereses, necesidades y conflictos a través del texto. Por su parte la antropología cultural intenta descubrir las representaciones, escenarios, modelos que el autor del texto presupone conocidas por el lector. La Third Quest pretende recomponer de esta manera el mundo en que vivió Jesús y no sólo unas cuantas frases desencarnadas de él. Hay que buscar el Sitz im Leben de Jesús.

5) La toma en consideración de fuentes extracanónicas es otro rasgo bastante característico de esta tercera fase. Se privilegian de manera especial la Fuente Q y el Evangelio de Tomás, pero también otras reconstrucciones o fragmentos de otros evangelios o papiros. No todos están de acuerdo en el valor que se deba conceder a la literatura extracanónica, pero puede afirmarse que todos suscribirían el pincipio de que el Jesús histórico debe investigarse independientemente de los límites del canon. En ocasiones estas fuentes conservan los dichos de Jesús en un estado más primitivo que los evangelios canónicos. Posiblemente aquí termine el consenso; algunos dan un paso más: dan su preferencia al Evangelio de Tomás y a otras fuentes hipotéticamente reconstruidas. Es el caso de J. D. Crossan, quien entre las fuentes más antiguas (años 30-60 d. C.) no coloca ninguna que sea canónica, a no ser algunas cartas de Pablo.

Estos principios básicos característicos de la Third Quest no son suficientes para imponer un consenso en la investigación ${ }^{12}$. Como en la Old Quest parece que los autores están obligados a reflejar su imagen cuando lo que intentan es dibujar la de Jesús. No se trata de diferencias de matices; en algún caso la comprensión de Jesús es muy diversa. Se ha presentado a Jesús como mago, santón judío, teólogo de la liberación, profeta escatológico, filósofo cínico, predicador de una sabiduría bastante limitada, etc.

Dentro de la Third Quest, sin duda, el grupo que más ha llamado la atención es el Jesus Seminar. Por los puntos de vista novedosos, por la misión que quieren desarrollar, por la manera de presentarse ante los medios de comunicación social y por el modo innovador de alcanzar y exponer el consenso entre ellos han causado un impacto fuerte en Norteamérica y consiguientemente en las revistas especializadas del mundo. Ellos han sido los que han hecho que se tome conciencia de que estamos en una fase distinta de la inves-

12. M. J. BORG, Jesus in Contemporary Scholarship. Valley Forge, 1994, 18-43. B. WITHERINGTON III, The Jesus Quest. The Third Search for the Jew of Nazareth. Downers Grove, 1995. 
tigación de Jesús. Han conseguido simbolizar la controversia sobre el Jesús histórico. No son los únicos desde luego, pero sí los que con más claridad han roto con la investigación anterior.

\section{El Jesus Seminar}

\subsection{Organización}

El Jesus Seminar es una asociación relativamente pequeña ${ }^{13}$ de profesores y especialistas que se encuentran dos veces al año para debatir acerca del Jesús histórico. Nace el año 1985 bajo el impulso y la iniciativa de Robert W. Funk, ya conocido por sus dotes organizativas como anterior secretario de la Society of Biblical Literature, y J. D. Crossan; al principio consiguen reunir a unos 30 especialistas del N. T.14. Ahora superan ampliamente este número. En la obra cumbre de la asociación, The Five Gospels ${ }^{15}$, se da la cifra de 74 Fellows que en principio serían los participantes en el seminario. Decimos en principio porque en realidad los que participan en la reuniones regularmente y votan son entre 30 y 40 . Cuentan además al parecer con 200 miembros (Associate Members) que contribuyen al mantenimiento del seminario. Pertenecen a diversas confesiones cristianas; hay también judíos. Está sostenido el seminario por el Westar Institute de Sonoma, California; una editorial, la Polebridge Press, edita sus publicaciones.

No está asociado a los dos grandes organizaciones de especialistas de la Biblia: ni a la Society of Biblical Literature ni a la Studiorum Novi Testamenti Societas, que tienen su origen en Norteamérica e Inglaterra respectivamente y que ahora son internacionales y muchos más numerosas.(La primera supera los 6.000 miembros)

El Seminario no representa el punto mayoritario de los estudiosos ni de los especialistas del N. T.; solamente presenta los puntos de vista de un grupo que se ha asociado libremente por una opción personal previa; por tanto no representan a las universidades en las que trabajan. Evidentemente, dados los presupuestos del Seminario, los que optan por asociarse tienen una muy precisa mentalidad referente a los temas de la investigación bíblica. Todos son

13. Ellos no piensan así. Creen representar "a wide array of Western religious traditions and academic institutions" (R. W. FUNK-R. W. HOOVER And THE JESUS SEMINAR, The Five Gospels. The Search for the Authentic Words of Jesus. New York 1993, ix)

14. The Five Gospels, 34.

15. p. 533-537. Al parecer el grupo se ha reducido. La lista que se ofrecía en la primera obra del grupo enumeraba 96 (The Parables of Jesus.- Red letter edition. Sonoma 1988, 94-97. 
seguidores del método histórico-crítico, que completan con el uso de la sociología y de la antropología. En su mayoría son norteamericanos, aunque algunos son de Canadá y de Sudáfrica. Europa no tiene ningún representante. Famosas universidades americanas no tienen ningún miembro en la asociación. Son particularmente numerosos los que trabajan o se han graduado en la Claremont Graduate School. Tratándose de un número tan reducido, el Jesus Seminar no representa, aunque a veces parecen pretenderlo, la "ciencia" del N.T. sobre el Jesús histórico, sino solamente una determinada orientación profundamente liberal en lo religioso, desde luego nada conservadora. Esta última tendencia, representada por muy pocos miembros, en ningún caso puede poner en peligro el resultado de las votaciones.

Es también claro que nace para contrarrestar los puntos de vista de los predicadores de la televisión o "Tele-evangelismo". Y esta postura, aunque sea legítima, les priva de serenidad. A veces se presentan como víctimas de represalias ${ }^{16}$.

\subsection{Objetivo}

Quieren realizar lo que Bultman hizo para su generación: exponer una historia completa de la tradición sinóptica; se diferencian de Bultmann, porque éstos incluyen el material extracanónico. Más concretamente lo que pretenden es evaluar todas las parábolas y dichos atribuidos a Jesús en los tres primeros siglos, juzgar su autenticidad según criterios objetivos y distinguir lo que Jesús dijo de aquello que él no dijo, aunque le sea atribuido.

Estos objetivos los pretenden realizar con una mentalidad bastante diferente de los demás investigadores. Ellos se consideran "misioneros". Están convencidos de hacer una obra buena para el mundo cristiano.

Afirman que el nivel de conocimiento de las materias bíblicas por parte del público es igual a cero. La iglesia ha fracasado en este intento de exponer los evangelios a los laicos. Muchos, creen ellos, ni siquiera conocen el nombre de los cuatro evangelios. A pesar de que en las universidades y facultades se enseñan estas cosas, al público no llegan ${ }^{17}$. No sólo acusan a la iglesia de este control que ha ejercido sobre la Biblia, sino también a los especialistas del N. T., que se han limitado a exponer sus conocimientos en la clase o a sepultarlos en revistas científicas, que, por supuesto pocos leen, sobre todo, si como es habitual, los envuelven en una jerga especializada. Los eruditos han tenido miedo,

16. The Parables, xii-xiii.

17. The Parables, ix-xiii. 
señalan ellos, de salir a la palestra pública por temor a armar un revuelo público.

Notemos esta conciencia de misión que, aunque resulta singular, no es única en la historia de la investigación. Debe notarse cómo a Bultmann le movía una parecida conciencia misionera: el cristianismo es inconciliable con la moderna mentalidad científica; no se puede seguir creyendo en la intervención de seres sobrenaturales en el mundo de la objetividad y al mismo tiempo vivir en el mundo moderno que se cree cerrado, siguiendo leyes fijas y férreas. Por lo mismo hay que reducir el cristianismo, desmitificarlo y reinterpretarlo para que sea inteligible para el hombre de hoy's.

No es muy diferente la misión del Jesus Seminar, al menos tal como la presenta sus miembros más señalados.

En el discurso de apertura del primer encuentro, el director Robert W. Funk ya señalaba los objetivos concretos. Constataba que los cristianos no quieren al Jesús real, sino el Jesus mítico, cúltico a quien poder adorar. Es misión del Jesus Seminar presentar al Jesús real.

Mientras que notamos la ingenuidad de esta afirmación (el Jesús real es inalcanzable), observemos que no pretenden buscar al Jesús cúltico a quien los cristianos adoran.

Es claro que la historia nunca puede justificar la fe o el Jesús del culto. Pero en estas afirmaciones se sorprende un parecido grande con los intentos de la Old Quest. Entonces "la separación ... entre Jesús y los evangelios no nacía de la conciencia científica y metodológica de que los evangelios son escritos confesionales... y que necesitan que los leamos como tales. No, sino que nacía de la sospecha de que el Jesús que se nos describe en los Evangelios no es el mismo que el Jesús histórico. Interesaría liberar a Jesús de las garras del dogma y presentarlo tal como fue en realidad"19. Dicho de otra forma se partía del supuesto de que Jesús no pudo haber sido el que nos dibujan los evangelios.

El Jesus Seminar va igualmente a la búsqueda de un Jesús competidor con el diseñado por los Evangelios. Hay que liberar a Jesús de los Evangelios. ¿Cómo rescatarlo?. Lo confesaba el director del Seminario en la primera reunión: "necesitamos una nueva narrativa de Jesús, un nuevo Evangelio, si queréis, que coloque a Jesús diferentemente en el gran esquema, la historia épica... Hoy tenemos dificultades para aceptar el relato bíblico de la creación y la conclusión apocalíptica en sentido literal"20.

18. El parecido con Bultmann se aprecia en frases como ésta: "la controversia religiosa contemporánea se debate en torno a si la visión del mundo reflejada en la Biblia puede ser mantenida en esta edad científíca y retenida como artículo de fe". (The Five Gospels, 2).

19. J. GNILKA, Jesús de Nazaret. Mensaje e Historia. Barcelona 1993, 16.

20. R. FUNK, Forum 1/1(1985)11-12. 
Aquí ya se halla anunciado lo que de hecho van a hacer: un evangelio que presente a un Jesús no mítico y no escatológico'21.

Recientemente Robert W. Funk ha anunciado un nuevo Canon según el Jesus Seminar22. Es la conclusión lógica.

\subsection{Sistema de trabajo}

La metodología seguida en el trabajo común se halla expuesta en las publicaciones del seminario. Editan desde el comienzo una revista Foundations and Facets Forum (o más brevemente Forum) dirigida por Robert W. Funk, que desde el principio adquiere el papel de protagonista de la mayor parte de las iniciativas y portavoz del grupo. En 1988 publican The Parables of Jesus. Red Letter Edition. Comenzaron el examen por las parábolas, porque a su juicio y en ésto no son los únicos, en ellas se encuentra la tradición más segura acerca de Jesús. Luego The Gospel of Mark. Red Letter Edition de 1991. Y finalmente la obra cumbre hasta ahora The Five Gospels. Este libro es el fruto de ocho años de trabajo. Contiene una traducción propia (llamada Scholars Version) de los 4 evangelios canónicos y del evangelio de Tomás. Presentan en el libro los dichos de Jesús en colores: rojo, rosa, gris y negro según el grado de autenticidad. El Seminario ha comenzado una segunda fase: el estudio de los hechos de Jesús.

Conforme con la exigencia que presentan de que el Critical Scholar (y los miembros del Jesus Seminar se tienen por tales) debe conocer la Computer Science, se entiende su método de trabajar que tiene estas etapas:

1) Compilar una lista en bruto de todas las palabras atribuidas a Jesús en los tres primeros siglos. Estos dichos debían ponerse como paralelos, de tal manera que todas las versiones del mismo dicho aparecieran una al lado de otra. Una primera tarea fue hacer el inventario de las palabras de Jesús. Se adoptó el libro de trabajo de J. D. Crossan Sayings Parallels. Contiene más de mil23 versiones de 503 dichos, clasificados en cuatro categorías: parábolas, aforismos, diálogos e historias que incorporan palabras de Jesús. Abarca los escritos canónicos y extracanónicos de los tres primeros siglos (fecha tope el

21. Teniendo en cuenta estas afirmaciones, puede preguntarse si tienen sentido los ataques que dirigen a la iglesia por no haber sabido ni querido presentar a los fieles el Jesús real. ¿Que interés puede tener la iglesia en presentar a un Jesús diferente del de los Evangelios?

22. J. P. MICHAUD, "Un Etat de la recherche sur le Jésus de l'Histoire": Eglise et Théologie, 26(1995) 144, nota 1.

23. En The Five Gospels, 35 se da la cifra de más de 1.500 . 
313, año del edicto de Constantino). No se tiene en cuenta los límites canónicos. El libro de Crossan se convirtió en libro oficial del Jesus Seminar.

2) Clasificar la lista y determinar, sobre la base del consenso científico, qué palabras probablemente son eco o reflejan la voz de Jesús, y qué palabras pertenecen a los siguientes estratos de la tradición.

Para ello se reunían dos veces al año (primavera y otoño). En cada reunión se sometían a votación los dichos de Jesús que van a ser estudiados en la siguiente reunión. De esta manera los miembros del grupo tienen tiempo para estudiar, intercambiar informes y debatir a nivel informal. Tenía también lugar una votación sobre los dichos que van a ser discutidos. Los resultados se usaban para determinar el tiempo de discusión. Cuando había un fuerte consenso sobre un dicho, no se discutía; el seminario se dedicaba a los discutidos. Los encuentros se reservaban para argumentar y debatir. La cuestión era entonces, cómo saber si había un consenso sobre un dicho particular y cómo medir la magnitud de tal consenso. Se imponía la votación como el medio más fácil para obligar a los estudiosos a pronunciarse y la edición de los textos en colores se veía como el medio más rápido para dar a conocer al gran público los resultados. La votación se efectuaba mediante bolas de color depositados en una caja, no necesariamente de forma secreta.

Votar desde luego es llamativo; ellos argumentan que no tratan de determinar la verdad histórica por medio de los votos, ni manipular la palabra de Dios $^{24}$; lo único que quieren es saber si existe un consenso entre los estudiosos sobre lo que Jesús realmente dijo y qué no dijo y quieren dar a conocer los resultados de sus deliberaciones al público de una manera clara. Aducen, además, que es el sistema que se usa en el comité de edición del texto griego del N. T. y frecuentemente en los comités encargados de la traducción de los libros de la Biblia25. No obstante, no pueden negar que la impresión que el público en general saca es otra: la mayoría decide sobre la verdad.

Han convenido en dar el siguiente valor a los colores. Los colores rojo y negro son las categorías básicas: el color rojo para los dichos que se aproximan o son ciertamente de Jesús, mientras que el color negro señala los dichos

24. The Parables, ix.

25. Este paralelismo con los comités encargados de la traducción sólamente hasta cierto punto es válido. Estos comités de la United Bible Societies están compuestos por expertos internacionales que ocupan una postura media reconocida públicamente. Esto no es verdad de los miembros del Jesus Seminar. Además en los comités de traducción las opiniones de los que disienten con las razones que aducen son incluidas en el aparato crítico. Porque en definitiva no tiene mayor valor que sean más los que estén a favor de una opinión, sino las razones son las que permiten al lector escoger con conocimiento de causa. Cfr. BOCKMUEHL,M. This Jesus, Martyr, Lord, Messiah. Edinburgh,1994, 185, nota 45. 
no representativos de él. Más tarde la práctica indujo al grupo a cambiar el valor de los votos: se creyó necesario añadir otras dos categorías intermedias: el color rosa, que es una forma débil del rojo, y el color gris que es una forma debilitada del negro.

El seminario adoptó dos interpretaciones oficiales de los cuatro colores:

Opción $1^{a}$ : Rojo: yo incluiría este dicho inequívocamente en la base de datos para determinar quién fue Jesús; rosa: yo incluiría este dicho en la base de datos con reservas o modificaciones; gris: yo no lo incluiría en la base de datos primaria, pero podría hacer uso de parte del contenido para determinar quién fue Jesús; negro: yo no lo incluiría en la base de datos primaria.

Opción 2a: Rojo: Jesús indudablemente dijo esto o algo muy parecido a esto; Rosa: Jesús probablemente dijo algo semejante a esto; gris: Jesús no lo dijo, pero las ideas contenidas son afines a las propias de Jesús; negro: Jesús no lo dijo, representa la perspectiva o contenido de tradiciones tardías o diversas.

Hay una tercera interpretación de los votos más popular y simple, aunque no es oficial:

Rojo: That's Jesus!

Rosa: Sure sounds like Jesus.

Gris: Well, may be.

Negro: There's been some mistake26.

Por la formulación de las opciones se percibe claramente que el color rosa y el color gris indican reservas, bien sea sobre el grado de certeza de los votantes, o bien sobre las modificaciones que los críticos creen que el dicho ha sufrido 27 .

De todas maneras la distinción entre el color rojo y el rosa se presta a equívocos. Ellos mismos admiten con razón que los transmisores de la tradición oral ordinariamente no recuerdan las expresiones exactas de los dichos o de las parábolas de Jesús que intentan citar. No tienen a mano notas escritas que puedan consultar y las versiones que ellos mismos han escuchado varí$a^{28}$.. Además Jesús habló arameo y la tradición llega hasta nosotros en griego. Por tanto, difícilmente uno puede afirmar "Jesús dijo esto o aquello inequívocamente (que sería lo propio del color rojo), sino que tendrá que decir que "Jesús dijo algo semejante a esto" (lo propio del color rosa); las dos cosas, en cambio, deben figurar en una base de datos para averiguar lo que

26. The Five Gospels, 36-37.

27. The Five Gospels, 36.

28. The Five Gospels, 27. 
dijo Jesús. Por contra los dichos en color gris y negro no gozan de garantía y no deben ser usados para reconstruir la imagen de Jesús.

En el escrutinio de votos se sigue el sistema proporcional y ponderado, no el mayoritario. De esta manera al voto rojo se le dan 3 puntos; al amarillo, 2; al gris, 1 y al negro, 0 . Los puntos son sumados en cada votación y dividido por los votantes para ver el porcentaje medio. Así un dicho de Jesús que reciba un promedio de 0.75 o más bajo será impreso en negro; de 0.751 hasta 1.500 será gris; de 1.501 hasta 2.250 será amarillo; y de 2.251 para arriba será rojo. Este sistema simplifica otro procedimiento anterior que se comprobó más inconveniente.

A veces los resultados no eran concluyentes, entonces los dichos eran estudiados en las siguientes reuniones ${ }^{29}$. Los resultados eran publicados en la revista Forum. Luego aparecen en las obras anteriormente mencionadas.

El sistema de votación no es democrático, si por democracia se entiende buscar mayorías y que éstas predominen. Con la manera que usan de computar los votos, puede darse el caso que la mayoría vote los colores rojo y rosa y el texto deba escribirse en gris, porque hay bastantes bolas negras. Esto sucede expresamente con Mc 13,28-29. La mayoría votó rojo y rosa, pero se impuso el gris por los muchos votos en negro que hubo. Parecido es el caso de Mt 6,5s; el 58 \% votó rojo y rosa y el 27 \% negro; tuvo que imprimirse en gris. Naturalmente puede suceder lo contrario en teoría: que una mayoría (más del 50\%) vote negro o gris y tenga que imprimirse en rosa por el amplio número de votos rojos.

Claramente el sistema de votación está orientado contra la autenticidad ${ }^{30}$. El dicho de Jesús tiene que probar su autenticidad, no al revés. Pero los miembros del Seminario confiesan que el sistema es conforme con el escepticismo metodológico que es el principio básico de los participantes: en caso de duda, hay que desechar la autenticidad ${ }^{31}$. En esta afirmación los miembros del Jesus Seminar no dicen nada nuevo. Es sabido que durante la New Quest se discutió profusamente acerca del criterio de presunción histórica. N. Perrin ${ }^{32}$, por ejemplo, afirmaba que dada la naturaleza del material evangélico, la autenticidad es la que debe ser probada y no al revés. Otros opinaban lo contrario ${ }^{33}$. Hoy parece más lógico pensar que el que quiere afirmar algo, sea la autenticidad o la inautenticidad, debe cargar con el peso de probarlo ${ }^{34}$. Y es

29. The Parables, 20.

30. "The Vote tends to be skewed towards black end of the spectrum" (The Parables, 21).

31. The Five Gospels, 37.

32. Rediscovering the Teaching of Jesus. London 1967, 39.

33. N. J. McELENEY, "Authenticating Criteria and Mark 7, 1-23: CBQ 34(1972)445-448. 34. J. P. MEIER, A Marginal Jew, I, 183. 
que hay también motivos para presumir la historicidad. Los discípulos debieron tratar la tradición con más o al menos con el mismo respeto que los discípulos de Hillel y Shammai. Por otra parte, dado que Jesús fue criticado por los judíos, los discípulos debieron sentir la necesidad y el interés de recordar, preservar y defender a su maestro de las acusaciones ${ }^{35}$.

Sin duda lo que más ha llamado la atención es el sistema empleado para dar a conocer los resultados de los estudios del seminario. El medio puede ser inocente y bien intencionado, pero por dos razones es peligroso. Quien conozca el mundillo de los estudiosos del Jesús histórico sabe que frecuentemente hay una especie de competición entre ellos a ver quién es más crítico y por tanto más tacaño a la hora de calificar los dichos de Jesús.

De otra parte fomenta el espectáculo, atmósfera no muy apta para una estudio ponderado. Pero precisamente esto es lo que pretenden los organizadores. El llamar la atención, atraer a la prensa forma parte de su objetivo. En efecto los congresos semestrales son organizados en diferentes ciudades de Estados Unidos con el fin de encontrarse con la prensa local escasa de noticias y ávida por tanto de novedades, sobre todo si son picantes. Y ciertamente es atractivo observar las votaciones públicas hechas por estudiosos sobre la autenticidad o no de las palabras de Jesús. El encuentro con la prensa local, la presencia de periodistas en las votaciones, las entrevistas con los miembros del Jesus Seminar forman una especie de escenificación sorprendente y responden al objetivo que buscan. Llamar la atención es el primer elemento para que la exposición de las opiniones llegue rápidamente al público. La búsqueda de los medios de comunicación es de este modo una constante de los miembros del grupo. ¿No hay que atribuir a la búsqueda de la publicidad, el hecho de que Paul Verhoeven sea miembro del Jesus Seminar? Este no es conocido por sus investigaciones bíblicas, sino porque ha sido director de películas tan famosas como Robocop, Instinto básico y Showgirls.

\subsection{Presupuestos del Jesus Seminar}

Los miembros de Jesus Seminar son profesores e investigadores que se han dedicado a la investigación del Nuevo Testamento, y concretamente a los estudios del Jesús histórico. Por lo mismo se creen continuadores de una larga tradición y construyen sus opiniones sobre los hallazgos de las generaciones precedentes que desde fines del s. XVIII han dedicado ingentes esfuerzos a la

35. B. WITHERINGTON III, The Jesus Quest, 48. 
causa del Jesús histórico que tanto ha interesado a la civilización cristiana occidental.

\subsubsection{Presupuestos Generales}

Los supuestos de los que parten son varios. Algunos son comunes a la mayoría de los investigadores; de ellos trataremos brevemente en primer lugar. Luego hablaremos de dos principios básicos para ellos: el aprecio del Evangelio de Tomás y la valoración que hacen de la fuente Q. En estos dos puntos ellos caminan más solos.

Nada especial y novedoso se sorprende en las afirmaciones que hacen sobre la fecha, carácter y teología de cada uno de los evangelios sinópticos ${ }^{36}$. Mc está escrito poco después del año 70 d. C. Es el responsable de haber creado el primer esquema cronológico de la vida de Jesús. Puede también atribuírsele el haber unido el relato de la vida pública con la pasión. Marcos refleja la opinión de la comunidad cristiana de su tiempo que espera que Dios sin tardar lleve al mundo hacia el final en una conflagración apocalíptica ${ }^{37}$. Mateo escribe su evangelio en la década de los ochenta, cuando la comunidad busca su identidad frente al judaismo; refleja el sufrimiento de muchos cristianos al ser expulsados de la sinagoga. Lucas es del mismo periodo. Su preocupación es el desarrollo de la comunidad entre los gentiles ${ }^{38}$.

Sobre el problema Sinóptico son partidarios, junto con la mayoría de los investigadores, de la teoría de la doble fuente que ellos llaman de las cuatro fuentes: Mc, Q, MS y LS. Estas dos últimas son los materiales propios de Mt y Lc respectivamente.

Su dependencia de la escuela de la historia de las formas es más que notable. Rechazan la secuencia de la vida de Jesús, como es normal en la investigación científica desde K. L. Schmidt. Una vez disuelta la conexión de los diversos episodios, el estudio debe hacerse sobre los materiales tradicionales que tocante a los dichos clasifican en cuatro clases: parábolas, aforismos, diálogos e historias (éstas tienen unas palabras de Jesús; son los apotegmas de Bultmann). Estas tradiciones son perfectamente aislables en su contexto y tienen sentido en sí mismas.

36. El Evangelio de Juan, como es normal, juega un papel casi nulo en la investigación del Jesús histórico. Los miembros del Jesus Seminar sólo han encontrado un dicho que puede remontar a Jesús y lo ponen en color rosa. Pero es un dicho (Jn 4,44) que tiene paralelos en los Sinópticos.

37. The Parables, 12

38. Ibid. 13 . 
Carentes de novedad son también sus afirmaciones sobre la redacción de los evangelistas que citamos a continuación:

a) Los evangelios agrupan dichos y parábolas en conjuntos y complejos que como tales no remontan a Jesús.

b) Los evangelistas proveen de contextos nuevos a dichos de Jesús y también inventan contextos narrativos donde colocan palabras de El. Bultmann hablaba de escenas ideales.

c) Los evangelistas añaden nuevos dichos o los interpretan y comentan con nuevas palabras. J. Jeremías ofrecía muchos ejemplos tomados de los finales de las parábolas.

d) Los evangelistas redactan o alteran el tenor de las palabras de Jesús para hacerlas más conformes a sus puntos de vista.

e) Los evangelistas ponen en boca de Jesús sentencias tomadas del A. Testamento o del acervo cultural o sencillamente de su propia cosecha.

f) A veces palabras de Jesús son suavizadas en el curso de la transmisión. Hay indicios numerosos de la adaptación de las palabras de Jesús a la vida de la comunidad; de lo que resulta una cristianización del mensaje de Jesús. Todas estas observaciones pueden compararse con lo afirmado por el Concilio Vaticano II $^{39}$ sobre los estratos de la tradición evangélica y no se sorprenderá novedad relevante alguna. Admitir tres estratos o etapas en la tradición evangélica es comúnmente afirmado. Una lectura suficientemente ilustrada de los evangelios observa la colocación arbitraria de los materiales en los evangelios. Los autores crean contextos para los dichos con desparpajo. Interpretan los materiales con gran libertad y de diferentes maneras. No se limitan a conservar y exponer las tradiciones acerca de Jesús, sino que las adaptan a las nuevas necesidades. Debido a estos factores los estudiosos han sido siempre muy cautos a la hora de recuperar las palabras originales de Jesús.

No solo la redacción de los evangelistas y la comparación de los evangelios entre sí nos obligan a ser cautos al momento de juzgar la historicidad, también la etapa anterior presenta obstáculos que los "Fellows" del Jesus Seminar recuerdan. Suponen con razón que la tradición anterior debió ser oral, y ésta tiene tiene sus leyes que resumen con especial esmero.

En principio nada que oponer al axioma fundamental enunciado por ellos: "Solamente los dichos y parábolas que pueden ser retrotraídos al periodo oral, 30-50 a. C., pueden posiblemente haber tenido su origen en Jesús"40.

39. Dei Verbum, nr. 19; el Catecismo de la Iglesia Catolica n. 126 expresamente habla de "tres etapas" de la tradición evangélica.

40. The Five Gospels, 25. 
El plazo viene impuesto por la duración de la vida de los testigos. Admitido este principio, queda ahora por fijar cuáles son en teoría las características de una tradición oral. Ellos señalan en primer lugar la siguiente: La memoria oral retiene mejor los dichos y anécdotas, cortas, provocativas, memorables y repetidas; efectivamente encuentran que las palabras de Jesús más recordadas en los evangelios tienen forma de aforismos y parábolas.

Encuentro que esta regla no es nueva. Ya M. Joussse ${ }^{41}$ señalaba que gran parte del material se adaptaba a esta regla de la tradición oral, aunque él no insistía tanto en la brevedad del dicho, cuanto en lo llamativo y pintoresco y en el lenguaje concreto en oposición a la disertación abstracta y profunda, más difícil de recordar.

Más concretamente y queriendo indicar rasgos característicos del lenguaje de Jesús (y sólo el hablar distinto puede ser individualizado) señalan estas reglas:

-Las palabras de Jesús son contra-culturales social y religiosamente.

Es fácil sorprender en estas palabras el criterio de desemejanza si no en su forma tajante como en la New Quest, sí como se propone en la Third Quest, como un medio de sorprender lo distintivo de Jesús dentro del judaísmo. Es por ello por lo que los miembros del Jesus Seminar indican que las palabras de Jesús "sorprenden y chocan; proponen un vuelco de los roles o frustran las expectativas ordinarias" 42 .

Dicen que basan este criterio en varias de las grandes parábolas, tales como el samaritano (Lc 10,30-35, los trabajadores de la viña (Mt 20,1-15, el hijo pródigo (Lc 15,11-32, las bienaventuranzas (Lc 6,20-23), la exhortación a prestar a aquéllos de quienes no se espera la devolución (Tom 95,1-2). El herido por los ladrones no espera que un samaritano le ayude; el hijo pródigo no espera que le reciba su padre; los llamados a trabajar a última hora no esperan recibir el salario completo. En la otra parte de la historia aparecen frustradas las esperanzas de otros actores. Los llamados a primera hora no encuentran cumplida su esperanza de recibir más por su trabajo realizado; el hijo mayor se queja por no haber sido tratado con tanta magnanimidad.

Estiman que este criterio es de extraordinaria importancia para averiguar los dichos de Jesús 43 .

En la misma línea añaden un criterio más: los dichos y parábolas contienen exageraciones, chispas de humor y paradojas. Paradójicas son las biena-

41. Etudes de Psychologie linguistique. Le Style oral rythmique et mnemotechnique. Paris 1925.

42. The Five Gospels, 31.

43. The Five Gospels, 31. 
venturanzas, o el mandato de amar a los enemigos; exagerada es la cantidad de dinero que un siervo debe a su amo.

Y finalmente señalan que las imágenes usadas por Jesús son concretas y vivas, fecuentemente metafóricas y sin aplicación explícita, dejando de este modo la decisión a los oyentes.

Todos estos criterios tienen para ellos mucho valor, los destacan de manera especial y ampliamente los usan a la hora de determinar la autenticidad o no de los dichos y parábolas de Jesús.

Aunque no se trata de la misma clase de indicios, éstos, presentados como criterios por el Jesus Seminar recuerdan un tanto las características del lenguaje y del modo de hablar puestas de relieve durante la New Quest por H. Schürmann ${ }^{44}$. Notaba algunas notas específicas de las palabras de Jesús y de su modo de expresarse: lenguaje solemne, importancia dada a su palabra, lenguaje elevado y sacral, frecuencia de arameismos, uso amplio de imperativos, etc.

W. Trilling, por su parte, resumía algunas características típicas de la conducta de Jesús en su modo de actuar: "amor permanente a los pecadores, compasión hacia todos los que sufren y están oprimidos, severidad inexorable contra toda clase fariseísmo, cólera santa contra la mentira y la hipocresía. Y en todo ello y por encima de todo una orientación radicál hacia Dios, hacia el Señor de soberanía sin límites, que también es Padre"45. Estos tres sistemas de proceder y juzgar el material evangélico son diferentes, pero en realidad se reducen a un criterio que es el de la coherencia con el lenguaje, estilo o conducta de Jesús. Antes se les proponía como indicios, no como criterios y con toda razón, ya que no están exentos de caer en una petitio principii; se argumenta en base a expresiones o actos que no están asegurados previamente por otro criterio. Cabe la posibilidad de que se haya formado ya una idea global del modo de manifestarse Jesús, que después se encuentra atestiguada en el examen particular de las tradiciones, pero resulta que esta idea global ha salido precisamente del examen de las mismas.

En el Jesus Seminar este peligro existe. Dado que para ellos el material más seguramente genuino y auténtico son las parábolas, la "bedrock" de la tradición como las llaman, y estas características son discernibles mayormente en las parábolas, es conveniente observar si el Jesus Seminar no tiene una idea previa de las parábolas.

44. "Die Spache des Christus. Sprachliche Beobachtungen an den Synotischen Herrenworte": Biblische Zeitschrift 2(1958)54-84= Traditionsgeschichtliche Untersuchungen zu den Synoptischen Evangelien. Düsseldorf 1968, 83-108.

45. Jesús y los problemas de su historicidad. Barcelona 1970, 54. 


\subsubsection{Presupuestos específicos}

\subsubsection{Teoría de las parábolas}

No es preciso recordar aquí la viva discusión existente sobre la interpretación de las parábolas ${ }^{46}$. La tradición cristiana leyó las parábolas tratando de encontrar en ellas aplicaciones teológicas o morales. Es lo que se llama alegoría. Cada elemento narrativo de la parábola tiene su correspondencia en la realidad cristiana. Jülicher ${ }^{47}$ rompe con esta lectura y entiende las parábolas como una comparación desarrollada. Una idea se ilustra con otra idea similar. Estas dos partes convergen en un punto: punctum comparationis donde coinciden lo imaginado y la realidad.

El Jesus Seminar adopta la teoría "americana" de las parábolas. Arranca esta manera de pensar de la Nueva Hermenéutica y en el tema de las parábolas concretamente de Jüngel ${ }^{48}$ y P. Ricoeur ${ }^{49}$ que las entienden como un suceso de la palabra. Lingüistas y exegetas americanos la han desarrollado ampliamente 50 . La parábola es una metáfora y no una comparación. Las parábolas no son historias arrancadas de la realidad de la vida para ilustrar un verdad religiosa; menos aún son alegorías donde numerosos detalles tienen su contrapartida en la verdad religiosa. Son metáforas; no se pueden reducir, pues, al fenómeno de la sustitución ni al de la ilustración, sino que son la introducción de una palabra en un campo semántico ajeno y heterogéneo.

P. Ricoeur expone esta teoría con claridad. Señala que la metáfora no es el uso de palabras en sentido impropio, sino la creación de una tensión provocada por la juxtaposición de dos palabras que normalmente no pueden ir juntas, por ejemplo, un samaritano bueno. La introdución de una palabra en

46. Una breve, pero rica información sobre estas discusiones ofrece V. FUSCO, "Parábola/Parábolas": P. ROSSANO- G.RAVASI- A. GIRLANDA, Nuevo Diccionario de Teología bíblica. Madrid 1990, cols. 1390-1409. Es un resumen de la obra del mismo autor, Oltre la parabola. Introduzione alle parabole di Gesù. Roma 1983.

47. Die Gleichnisreden Jesu. I. Die Gleichnisreden in allgemeinen. II. Auslegung der Gleichnisreden der drei ersten Evangelien. Darmstadt 1976.

48. E. JÜNGEL, Paulus und Jesus. Eine Untersuchung zur Präzisierung der Frage nach dem Ursprung der Christologie. Tübingen 19866.

49. P. RICOEUR, La Metáfora Viva. Madrid 1980.

50. A. N. WILDER, Jesus' Parables and the War of Myths. Essays on imagination in the Scripture. Ed. J. Breech. Philadelphia 1982; R. W. FUNK, "Das Gleichnis als Metapher: W. HARNISCH (ed.), Die neutestamentliche Gleichnisforschung im Horizont von Hermeneutik und Literaturwissenschaft (WdF 575).Darmstadt 1982, 20-58; ID. Parables and Presence. Forms of the New Testament Tradition. Philadelphia 1982; J. D. CROSSAN, In Parables. The Challenge of the Historical Jesus. New York 1973; B. B. SCOTT, Jesus, Symbol-Maker for the Kingdom. Philadelphia 1981; ID., Hear Then the Parable. A Commentary on the Parables of Jesus. Minneapolis 1990. 
un campo semántico ajeno crea tirantez y tensión y libera el significado. Entender la metáfora no es reconocer la semejanza entre dos palabras, sino reconocer el choque provocado por la juxtaposición de campos semánticos incompatibles. La disonancia es constitutiva de la parábola e inaugura una posibilidad de sentido, pues es una innovación semántica. De aquí que las metáforas no puedan ser parafraseadas y trasladadas a un lenguaje proposicional. Por ello dan a conocer una nueva información de la realidad. El marco narrativo presenta la vida cotidiana. Un sembrador siembra... un hijo pide su parte a su padre... un patrón contrata jornaleros para su viña...De pronto en esta escena trivial y cotidiana se produce una extravagancia: el patrón paga a todos igual aplicando una política salarial estúpida, el padre acoge a su hijo despreciable que le ha abandonado y ha derrochado la fortuna, una abundante cosecha se da cuando la sementera ha sido un fracaso... En la ficción narrativa surge la discordancia de dos mundos o mejor dos órdenes de valores se ponen en tensión. La parábola dibuja otro mundo, donde los valores son distintos de los comúnmente admitidos.

Quien piense que es acertada esta interpretación de las parábolas, y los miembros del Jesus Seminar aceptan esta teoría, estarán siempre predispuestos a ver cosas chocantes por doquier. Consideran extravagante cualquier cosa que a otros parece normal. Por ejemplo, es extraño, dicen, que el pastor se ponga en búsqueda de una oveja perdida, o que un hombre que ha encontrado un tesoro en un campo lo entierre y venda todas sus posesiones y compre el campo aquel, o que un comerciante venda todo lo que tiene para comprar una perla de gran valor. Son, dicen, elementos extravagantes y extraños, y por ello marcas de ser originales de Jesús.

Personalmente pienso que cualquier pastor que nota la falta de un oveja va en su búsqueda. ¿Es una exageración que el dueño permita que una higuera siga en pie tras tres años de improductividad? Para los miembros del Jesus Jeminar por lo visto sís1. Como ejemplo en contra cabe citar que en la mayor parte de Castilla y León durante los años 1994 y 1995 prácticamente no hubo fruta alguna por las heladas. Me imagino que a ningún labrador se le ocurrió la hazaña de cortar los árboles frutales porque durante dos años no habían dado fruta.

Creo que bastan estos ejemplos para mostrar la extrema debilidad de los criterios apuntados por el Jesus Seminar para probar la autenticidad o la inautenticidad de las parábolas. Pero además es claro que incurren en una petitio principii: Tienen una teoría de la parábola como metáfora que incluye que sea

51. The Parables, 60. 
chocante, exagerada y extravagante y esto les lleva a ver estas cosas por doquier.

No negamos que ocurran sucesos inesperados en la narración de las párabolas; es cierto que se dan y sirven de valor por su fuerza argumentativa, pero no se les puede atribuir tanta importancia como para convertirlos en criterio de historicidad.

\subsubsection{Evangelio de Tomás ${ }^{52}$}

En los últimos años la consideración que se tiene de este Evangelio y de la fuente $Q$ ha cambiado notablemente. Los miembros del Jesus Seminar no han sido los pioneros en este tema, pero han aceptado estos puntos de vista con fuerza y han contribuido a un cambio de imagen del Jesús histórico.

En gran estima tienen los componentes del Jesus Seminar al evangelio de Tomás. No sólo le consideran como el quinto Evangelio ${ }^{53}$, sino que por su supuesta antiguiedad histórica le prefieren a los otros tres ${ }^{54}$.

Hacia 1900 se encontraron tres fragmentos en griego de un evangelio hasta entonces desconocido (POxy 1, POxy 654 y POxy 655)55. En 1945 entre los 52 tratados contenidos en 13 códices de la Biblioteca gnóstica de Nag Hammadi se encontró una copia en copto del Evangelio. Entonces se supo que los fragmentos anteriormente citados formaban parte del Evangelio de Tomás. A este evangelio se refieren Hipólito y Orígenes, quienes nos transmiten la noticia de que grupos heterodoxos usaban un "evangelio según Tomás".

Entre los fragmentos griegos y el texto copto hay diferencias en las expresiones y en el orden de las sentencias. Como además se observan dichos de Jesús duplicados, es claro que este evangelio conoció varias ediciones.

El evangelio contiene 114 sentencias del Señor, introducidas por la fórmula "Jesús dijo" o bien alguien se dirige a Jesús y éste responde. Todas ellas se presentan como escritas por Tomás el "mellizo". Carece de la historia de la pasión, no contiene relatos ni historias acerca de Jesús, ni siquiera, y esto es notable, alusión alguna a los relatos, por ejemplo, a los milagros.

52. Puede verse la versión y el comentario de M. ALCALA, El Evangelio copto de Tomás. Salamanca 1989; otra versión y comentario por modernos neo-gnósticos puede verse en E. GILLABERT- P. BOURGEOIS- Y. HASS, Evangelio según Tomás. Presentación y comentarios. Barcelona 1992.

53. A él se refieren en el título del libro The Five Gospels.

54. Cfr. también PATTERSON, S. J., The Gospel of Thomas and Jesus. Sonoma 1993.

55. Pueden verse estos fragmentos y su traducción castellana en A. de SANTOS OTERO, Los Evangelios Apócrifos. Madrid 19632, 87-95. 
El paralelismo con los evangelios sinópticos es notable. La mitad del material de Tomás grosso modo tiene paralelos en los evangelios: 47 paralelos con Mc, 40 con Q, 17 con Mt, 4 con Lc y 5 con Juan; esta estadística incluye los dichos duplicados. Aproximadamente unos 65 dichos o parte de dichos son exclusivos de Tom. De todos los Evangelios apócrifos es sin duda el más interesante para la investigación del Jesús histórico y por ello mismo el más estudiado y más discutido.

Se discute la época en que fue escrito. Los papiros griegos no son posteriores al $140 \mathrm{~d}$. C. Es común pensar que el texto copto es una versión del texto griego. Pero la edad de los papiros conservados no dice nada acerca de la antigüedad de la obra. Por el logion 71 parece manifiesto que el Evangelio de Tomás es posterior a la destrucción de Jerusalén del año 70. Pero como quiera que el escrito debió tener diferentes ediciones, tampoco esta fecha es muy indicativa. Lo característico del Jesus Seminar es atribuirle una alta antigüedad, y al mismo tiempo afirmar que la tradición representada por Tomás es independiente de la tradición Sinóptica56. Promotores de este cambio de opinión han sido entre otros $\mathrm{H}$. Koester ${ }^{57}$, que en este tema y en otros ha sido el inspirador del Jesus Seminar. Especulan que Tomás al igual que Q son de los años 50-60; en todo caso sus segundas ediciones son anteriores a los Sinópticos.

El problema principal es precisamente éste: ¿Qué relación tiene Tomás con los Sinópticos?

Ya durante la New Quest, J. Jeremías en su obra sobre las parábolas a partir de la $6^{a}$ edición analizaba también las que contiene Tomás. Encontraba que once de las parábolas de Tomás son paralelas a los Sinópticos; constataba que frecuentemente diversos rasgos están conservados en Tomás en un estado más primitivo y menos desarrollado que en los Sinópticos. El caso más claro, difícilmente negable, es la parábola de los viñadores homicidas, muy alegorizada en los Sinópticos, sobre todo en Mt, mientras que en Tomás carece de todas estas adiciones. Por otra parte notaba que Tomás también tenía sus adornos y desarrollos que manifiestamente eran secundarios ${ }^{58}$.

56. The Parables, xviii.

57. Entre sus numerosas publicaciones citamos una de las últimas, Ancient Christian Gospels. Their History and Development. London-Philadelphia 1990, 75-128. Una amplia exposición de los problemas tocantes al Evangelio de Tomas con amplia bibliografía puede verse en F. T. FALLON- R. CAMERON, "The Gospel of Thomas: A Forschungsbericht and Analysis": ANRW. Berlin-New York 1988, II, 25.6, 4195-4251.

58. La versión española de Las Parábolas de Jesús de J. Jeremías (Estella 1970) está hecha sobre la $7^{a}$ edición alemana de 1965; por lo que el lector de la versión española puede consultar los análisis de las parábolas del evangelio de Tomás. 
M. E. Boismard presentaba varios ejemplos (concretamente cinco) en los que, a pesar de algunos rasgos secundarios, Tomás, según él, sigue una tradición más antigua que nuestros evangelios actuales ${ }^{59}$. Estas opiniones eran, cuando fueron expresadas, minoritarias. Hoy el grueso del grupo del Jesus Seminar y otros autores opinan que Tomás representa una tradición independiente de la canónica.

Estas son las razones que esgrimen: 1) No hay un esquema de relaciones de Tomás respecto de la tradición sinóptica al estilo de las que manifiestan Mt y Lc respecto de $\mathrm{Mc}$; 2) $\mathrm{El}$ orden de los dichos en Tomás es casual, y a veces temático, pero en todo caso no refleja el orden de los Sinópticos; 3) Tomás no reproduce en ningún caso lo perteneciente a la redacción de los Sinópticos, ni las perspectivas teológicas propias de estos Evangelios; 4) Tomás pertenece a un género literario de colección de dichos que pronto dejó de escribirse; otros ejemplos son Q y la colección de parábolas que están detrás de Mc 4; 5) Y finalmente defienden que algunos dichos de Tomás son anteriores a los Sinópticos.

Estas razones son discutibles y discutidas. El argumento del orden, por ejemplo, no debe aducirse tan alegremente como ellos hacen por varias razones. Desconocemos la secuencia primitiva de los logia en Tomás, pues los fragmentos griegos y la versión copta no coinciden en el orden.

De otra parte, hay ejemplos curiosos. Tomás 65 reproduce la parábola de los viñadores homicidas que todos los sinópticos tienen (Mc 12, 1-12 par). Entre los adornos de la parábola los Sinópticos recogen el dicho sobre la piedra que desecharon los arquitectos. Resulta que Tomás tiene este dicho en el logion siguiente. ¿No será indicio de que Tomás conoce el orden sinóptico?. En Mt 6,1-18 se da una serie de normas sobre el ayuno, la oración y la limosna; estas prácticas piadosas son propuestas en el mismo orden en Tomás 6 y 14 .

Estos casos y otros pueden enjuiciarse de diferente modo. Puede discutirse quién depende de quién. No obstante, estos y otros más son citados porque se trata de textos de Mt que se consideran redaccionales; también se suelen aducir estos otros textos en que parece que Tomás depende del material propio de los evangelistas: Tom 14 respecto de Mt 15, 11; Tom 5 dependería de Lc 8,17; Tom 16, de Lc 12,51; Tom 55 dependería de Mt, 10,37s y de Lc $14,26 \mathrm{~s}^{60}$.

59. P. BENOIT- M. E. BOISMARD- J. L. MALILLOS, Sinopsis de los cuatro Evangelios. Bilbao 1977, T. II, 49. Concretamente señala estos textos de Tomás como más antiguos que nuestros evangelios: Tom 46= Mt 11,11; Lc 7,28; Tom 99= Mt 12, 49-50; Mc 3,3235; Lc 8,20-21; Tom 57= Mt 13,24-30; Tom 65= Mt 21,33-41; Mc 12, 1-9; Lc 20,9-16; Tom 100= Mt 12,15-22; Mc 12,13-17; Lc 20, 20-26.

60. Cita más textos de esta clase C. TUCKETT, "Thomas and the Synoptics": NT 30(1988)132-157. 
Debe, además, apuntarse que el mero hecho de que un dicho de Tomás se conserve en un estadio más primitivo, no supone que el evangelio como tal sea más antiguo que los Sinópticos. A veces evangelios más tardíos conservan versiones de dichos de Jesús en forma más primitiva.

Sea lo que fuere de esta dependencia o no de los Sinópticos, es una opinión generalizada que Tomás puede y debe usarse para reconstruir la enseñanza de Jesús, para el estudio de los orígenes y desarrollo de la tradición tras los evangelios sinópticos. Esto es un mérito del Jesus Seminar. No obstante, no debe olvidarse que el Evangelio de Tomás no es inocente. Ha venido al mundo de la ciencia en mala compañía: con una biblioteca gnóstica. También él tiene su teología. La mayor parte de los dichos son gnósticos ${ }^{61}$, y como tal adaptan los dichos de Jesús a esta doctrina, cuyos puntos principales son éstos: Jesús es salvador por su doctrina como revelador; la antropología es dualista; la escatología es presente; no hay dimensión escatológica futura; carencia de la soteriología de la pasión y resurrección; su doctrina ascética es apartarse del mundo (de los bienes, de la familia, de la sexualidad) y de las obras de piedad como ayuno, circuncisión y limosna.

El Jesus Seminar estima en gran manera el Evangelio de Tomás, pero resulta interesante saber por qué. No parece que sea porque enriquezca nuestra base de datos con nuevos dichos de Jesús. Solamente colocan en color rojo 3 dichos de Tomás: dos aforismos y una parábola y todos ellos están en los evangelios. No se atreven a colocar en color rojo ningún dicho de Jesús presente sólo en Tomás. En color rosa colocan 27 aforismos y parte de aforismos, pero todos ellos están también en los evangelios. En este mismo color ponen 10 parábolas, de las cuales sólo dos: el cántaro vacío (Tom 97) y el asesino (Tom 98) son exclusivas de este Evangelio62. Teóricamente, pues, proclaman estimar mucho a Tomás, pero a la hora de la verdad poco valor le reconocen. En la práctica confiesan que escasamente algún dicho de Tomás no presente en los sinópticos sea auténtico. El incluirle y darle tanta importancia, ¿no tendrá otra intención cual es el presentar a Jesús como predicador de un reino de Dios no escatológico? Más adelante veremos que efectivamente es así; pero antes veamos otro presupuesto importante de su hipótesis.

61. También los miembros del Jesus Seminar piensan que algunos dichos de Tomás son gnósticos (Parables, 11).

62. Estas dos parábolas fueron objeto de intenso debate entre los miembros. Las dos fueron sometidas a tres votaciones. La parábola del cántaro vacío sólo a la tercera votación consiguió el color rosa por un escaso margen. La parábola del asesino fue rechazada en las dos primeras votaciones y por ello aparece impresa en gris en la obra de Parables (p.63); sometida a nueva votación alcanzó el color rosa y así aparece en The Five Gospels (p. 524-525). 


\subsubsection{La fuente $Q$}

La fuente Q, a pesar de los ataques que ha sufrido, es una hipótesis aceptada por la mayoría de los investigadores. Con ella se cree explicar el origen del material de dichos comunes a Mt y Lc y ausente en Mc. No se ha encontrado ningún manuscrito que la conserve. Y esto es lo que obliga a hablar de hipótesis. No obstante, su existencia, para la mayoría entre los que se encuentran los miembros del Jesus Seminar, es indudable.

En los últimos años la consideración y el papel de Q en la investigación ha cambiado notablemente. El Jesus Seminar ha aceptado prácticamente de manera unánime la teoría de Kloppenborg sobre la existencia de estratos en la fuente $\mathrm{Q}$, que, por cierto en Norteamérica, ha tenido amplia aceptación.

La búsqueda de estratos en $\mathrm{Q}$ tiene ya una larga historia. Tras aplicarse la Redaktionsgeschichte a los evangelios sinópticos, se sintió la tentación de hacer lo mismo con $Q^{63}$, si bien aquí era más difícil, pues no existe otra obra con la que se pueda hacer comparación como sucede con Mt y Lc. En este caso hay que tratar de reconstruir el material fuente desde el texto mismo y luego usar la fuente reconstruida para identificar la redacción.

D. Lührmann ${ }^{64}$, P. Hoffmann ${ }^{65}$, S. Schulz ${ }^{66}$, A. Polag67, A. D. Jacobson 68 entre otros, trataron de distinguir entre la tradición y la redacción, señalando criterios que hicieran creíble la separación en estratos. Las opiniones son diversas y el número de redacciones, también.

En la historia de la investigación de la fuente $Q$ un punto de inflexión representó un artículo de J. M. Robinson'69, quien colocó la fuente $Q$ en el género literario de "dichos de los sabios", ya presente en el A. T. y en la literatura del Medio Oriente. La afirmación de que Q era básicamente un escrito de orientación sapiencial fue una intuición de largo alcance. H. Koester desarrolló ampliamente estas ideas y resaltó el carácter sapiencial de Q asociándolo al Evangelio de Tomás.

63. Suele considerarse que la aplicación de la Redaktionsgeschichte a Q comenzó con la obra de H. E. TÖDT, Der Menschensoln in der synoptischen Überlieferung. Gütersloh 1959.

64. Die Redaktion der Logienquelle (WMANT 33). Neukirchen-Vluyn 1969.

65. Studien zur theologie der Logienquelle (NTA 8). Münster 1972.

66. Die Spruchquelle der Evangelisten. Zürich 1971.

67. Der Christologie der Logienquelle (WMANT 45). Neukirchen-Vluyn 1977.

68. The First Gospel. An Introduction to Q. Sonoma 1992.

69. "LOGOI SOPHON: On the Gattung of Q": J.M.ROBINSON-H. KOESTER, Trajectories through Early Christianity. Philadelphia 1971, 71-113; recogido en J. S. KLOPPENBORG (ed.), The Shape of Q: Signal Essays on the Sayings Gospel. Minneapolis, 1994, $51-58$. 
Esta teoría del carácter sapiencial de Q, que recibió luego material escatológico y apocalíptico, fue difundida y profundizada por la amplia obra de $\mathrm{K}$. Kloppenborg70 que, a pesar de ligeras diferencias, representa el afianzamiento de la teoría de Robinson y Koester. El método es crítico-literario y trata de establecer criterios literarios y no teológicos para distinguir con ciertas garantías los estratos. De sus análisis concluye lo siguiente: elementos polémicos y amenazadores parecen ser adiciones a otros elementos anteriores de tradición sapiencial. De esta manera Kloppenborg postula dos estratos mayores en Q: uno más antiguo de carácter sapiencial que se compone de dichos dirigidos a la comunidad71; un segundo estrato, de carácter profético, se compone de adiciones polémicas contra "esta generación" 72 . El tercer estrato es breve ${ }^{73}$.

Aunque Kloppenborg nunca afirma que los estratos secundarios de la composición sean posteriores tradicionalmente, el Jesus Seminar da ese paso: el estrato más antiguo, el estrato original solo contendría palabras de sabiduría. Este estrato nos acercaría al Jesús histórico, pero un Jesús bastante diferente del habitualmente imaginado: un Jesús que anuncia la presencia de Dios en sus palabras. El primer estrato de $\mathrm{Q}$ es sapiencial como Tomás, partidario de una escatología realizada. Q después fue sometida a una redacción que habla del anuncio de juicio y de la futura venida del hijo del hombre que contrasta con la previa presencia de Dios en los dichos. Este cambio dejó su huella en el género literario: de colección sapiencial pasó a ser libro sapiencial y apocalíptico. La diferencia no es solamente literaria sino teológica; escatología futura frente a escatología realizada.

Una razón para pensar así es la relación que establecen entre Q1 y el Evangelio de Tomás; ya Koester vio a ambas obras como estrechamente relacionadas, siempre y cuando se purgue a $\mathrm{Q}$ de todos los elementos escatológicos y apocalípticos, especialmente los dichos sobre el Hijo del Hombre; aunque no son dependientes entre sí, ambas representan desarrollos de un evangelio sapiencial subyacente. De esta manera Tomás y $Q$ se refuerzan mutuamente. Es aquí donde se sorprende el interés del Jesus Seminar por Tomás. Este evangelio no dice nada nuevo sobre Jesús, pero sirve de soporte al Jesús sapiencial que creen descubrir en Q1.

70. The Formation of $Q$. Philadelphia 1987

71. Son estos $6,20-49 ; 9,57-62 ; 10,2-11.16 ; 11,2-4.9-13 ; 12,2-7.11-12.22-31.33-34 ; 13,24$; $14,26-27.34-35 ; 17,33$.

72. Este segundo estrato tiene textos de dos clases: son glosas breves estos textos: $6,23 \mathrm{c}$; 10,12.13-15.21-24; 12,8s.10; 13,25-30; 13, 34s. Los siguientes son textos más extensos: 3,7-9.16$17 ; 7,1-10.18-35 ; 11,14-26.39-52 ; 12,39-59 ; 14,16-24 ; 17,23-30.34-37 ; 19,12-27$.

73. $4,1-13 ; 11,42 d ; 16,17$. Deja sin atribuir a un determinado estrato $13,18-21 ; 15,4-7$; $16,13.18 ; 17,1-6$. 


\subsection{Resultados}

Queremos presentar y analizar ahora brevemente las dos obras importantes del Jesus Seminar.

\subsubsection{Traducción}

Además de estudiar la autenticidad del material evangélico, el Jesus Seminar ofrece un traducción propia que llaman Scholars Version, que tiene algunas singularidades.

En la traducción han querido seguir el lema siguiente: hacer que el lector no note que está leyendo una traducción ${ }^{74}$. Por tanto se trata de un tipo de versión que se suele llamar de equivalencia dinámica, es decir, que la traducción produzca en el lector contemporáneo la misma experiencia que tuvieron los primeros lectores u oyentes. En castellano sería equivalente a la NUEVA BIBLIA ESPAÑOLA75.

Aducen varias razones para hacer una traducción nueva. En primer lugar creen obligado incluir el Evangelio de Tomás (de ahí el título del libro The Five Gospels) y hasta ahora éste, piensan ellos, no ha sido traducido correctamente.

Por otra parte las versiones corrientes nivelan los evangelios; no respetan el estilo de cada evangelista; ellos quieren reproducir la voz singular de cada evangelista. Marcos tiene un estilo más coloquial, se aproxima al lenguaje de la calle. Une las frases con simples conjunciones y adverbios que traspasan la celeridad del relato a la vida de Jesús. Todo sucede en una rápida sucesión. Lucas es más literario y Mateo, más pausado. Quieren, además, presentar un lenguaje coloquial, cuando en el original se usa un giro del mismo carácter. No hacen ascos al uso del "common street language", es decir, al lenguaje duro y tosco, apartándose en todo caso de lenguaje piadoso; evidentemente evitan el lenguaje sexista.

Para conseguirlo la traducción pasó diversos controles, trabajaron y pulimentaron el trabajo diversos comités.

¿Cuáles son los resultados? En este tipo de traducción la obra nunca estará terminada; siempre se puede afinar más; no es fácil aceptar con el giro del idioma moderno que mejor responda al texto original. Por lo mismo es fácil

74. The Five Gospels, xiii.

75. Las cualidades que los miembros del Jesus Seminar atribuyen a su versión se parecen mucho a las que expresaban ya hace años de la suya L. ALONSO SCHÖKEl y J. MATEOS. Véase Nueva Biblia Española. Madrid 1975, 13-14. 
que en tales versiones al lado de aciertos felices que sorprenden y gustan, se adviertan otros casos donde la correspondencia deja bastante que desear.

Evidentemente juzgar estas traducciones es un facultad que sólo los que tengan como lengua materna el inglés americano lo pueden hacer. Por lo mismo nos limitaremos a algunos ejemplos sorprendentes.

Traducir reino de Dios por God's imperial rule difícilmente puede considerarse un acierto. Seguro que no sugiere en el americano el carácter alegre que Jesús pretendía imprimir a tal giro.

You Scholars and Pharisees, you Impostors! Damn you! es la versión de "¡Ay de vosotros, escribas y fariseos hipócritas!”. ¿Es correcta esta traducción?. La justifican diciendo que Woe (usual en las versiones inglesas) no es una palabra que el americano medio use. Si una persona quiere maldecir a otra usa más bien Damn you. Pero, ¿es una maldición lo que dice Jesús? Para Zorell76 es interjectio lugentis et comminantis. No parece que la expresión inglesa Damn you tenga el matiz de pena y comiseración por la suerte del amenazado como la tiene el original griego.

Traducen Cristo por Anointed. Literalmente es acertada, pero en el Evangelio ya no tiene significado literal. Los reyes entonces ya no se ungían, sino que se coronaban. Dudamos mucho de que el americano medio entienda lo que el Evangelista quería expresar. Notemos como curiosidad que traducen Hijo del hombre por son of Adam. Evitan el lenguaje sexista de este modo.

Por lo demás la frecuente lectura hará que suenen mejor ciertas expresiones que a primera vista extrañan. El tono coloquial a veces cautiva y resulta atrayente.

\subsubsection{Las Parábolas}

\subsubsection{Consenso, pero menos}

Es objetivo del Jesus Seminar determinar por consenso la autenticidad o la inautenticidad de las palabras de Jesús. Tratándose de las parábolas de Jesús, esto sólo lo han conseguido en un amplio sentido, como ellos mismos lo reconocen ${ }^{77}$.

76. Lexicon Graecum Novi Testamenti. Parisiis 1931, 953. U. Luz dice que "oyai" es starker Ausdruck der Klage. (Das Evangelium nach Matthäus. Neukirchen-Einsiedeln 1990, 194.

77. The Parables,23. 
Pocas son las aceptadas sin desavenencias como rojas o como negras. Abundan los colores intermedios, como era de esperar.

De las 60 versiones de las 33 parábolas, solamente 5 no tuvieron ni un solo voto negro: la de la levadura en las versiones de Mt $(13,33 \mathrm{~b})$ y Lc $(13$, 20b-21), el grano de mostaza en las versiones de Mc $(4,31-32)$ y en la de Tomás (20) y finalmente la de la perla en la versión de Tomás (76/1) que consideran mejor conservada que Mt 13,45-46.

Por contra 13 versiones de parábolas no reciben ni un solo voto rojo. Tales son la del asesino (Tom 98), la de las vírgenes necias (Mt 25,1-12), la de la puerta cerrada en las versiones de Lc $(13,25)$ y de Mt $(25,1-12)$, la de la red de pesca en las versiones de Tom (8) y Mt $(13,47-48)$, la de la cosecha (Tom 21,4), la del edificador de la torre (Lc 14,28-30), la del rey que va a la guerra (Lc 14,31-32) y la de los viñadores homicidas en las tres versiones sinópticas. Añaden otras tres que recogen de fuentes posteriores.

Hay algunos casos en los que la disparidad de criterios y las posturas irreconciliables son manifiestas.

La parábola del sembrador en sus diferentes versiones es un caso llamativo. En la versión de Mc (4,3b-8) recibe 28 votos rojos, 38 rosas, 3 grises y 31 negros. En la versión de Mt (13,3b-8), 28 rojos, 38 rosas, 0 grises y 34 negros. En la versión de Tomás (9) 21 rojos, 46 rosas, o grises, 33 negros. En la versión de Lc (8,5-8a) 21 rojos, 43 rosas, 0 grises, 36 negros. La constancia de los resultados hacen sospechar que los votantes se mantenían firmes en sus opiniones. Lo notable es también el alto número de las posturas extremas: votos rojos y negros.

La parábola del hombre rico de Lc $(12,16-20)$ recibe estos votos: 21 rojos, 52 rosas, 10 grises, 17 negros. Los votos sobre la versión de Tomás de la misma parábola son semejantes: $25,50,4,21$.

Nos han llamado la atención algunos casos curiosos. La parábola de la oveja perdida de Tomás (107) arroja este resultado 11, 36, 39, 14. Aquí extraña la generosidad de los 11 que votaron rojo. El buen pastor de la parábola va en busca de la oveja perdida porque se trata de la más grande y gorda. Alusión clara ésta al hombre perfecto, es decir, al gnóstico. El carácter 7secundario parece evidente. La parábola del tesoro escondido de Tom (109) recibe esta votación $18,43,21,18$. Hay un empate entre las bolas rojas y negras. Sin embargo, según la teoría de los participantes en el Seminario la versión de Mt $(13,44)$ dice algo extraño y chocante; la de Tomás es banal y además propone una conducta contraria a la recomendación que el mismo Tomás hace en el logion 95, por lo que debiera ser claro su carácter secundario.

En todos estos casos y otros que podrían citarse no han sido capaces de llegar a un consenso, ni siquiera a aproximarse a valores intermedios; el inter- 
cambio de información y las discusiones no han servido para limar las diferencias. Vista esta disparidad de opiniones, ¿tiene sentido que reprochen a los conservadores que creen en la inspiración divina del texto sagrado no coincidir al presentar la imagen de Jesús?78. Tampoco ellos apoyándose en criterios científicos llegan a coincidir. Y es que ni la fe ni la carencia de ella imponen una interpretacion única.

Por tanto y esta es nuestra conclusión, es falso que todo el grupo presente un frente común. La votación se proponía para adquirir el consenso; el resultado ha sido más bien ocultar la disparidad de opiniones escudándose en la mayoría, pues cabe sospechar que muchos votos rojos son de las mismas personas al igual que los negros.

\subsubsection{Las Parábolas siguen siendo una tradición segura.}

Siguiendo a J. Jeremías, el Jesus Seminar considera a las párabolas como la parte de la tradición más auténtica.

Las 33 parábolas son valoradas así:

5 en color rojo: $15 \%$ del total

16 en color rosa: $48.5 \%$.

6 en color gris: $18 \%$.

6 en color negro: $18 \%$.

Si se juntan las de color rojo y las del color rosa se llega a un $63 \%$ largo ${ }^{79}$. Es un número bastante elevado.

Quizá extrañe un tanto el $36 \%$ de negras y grises. Pero aquí debe tenerse en cuenta un dato importante. De estas doce parábolas que reciben los dos colores descalificantes, 5 se hallan solamente en escritos extracanónicos. Si se consideran las restantes siete canónicas aparte, el tanto por ciento de las inauténticas bajaría al 21. Estas son las que no debieran figurar en una base de datos para reconstruir el mensaje de Jesús: la parábola del portero (Mc 13,3435; Lc 12, 35-28) y la parábola de las diez vírgenes (Mt 25, 1-12) ${ }^{80}$, la parábola del rico y del pobre Lázaro ${ }^{81}$, la parábola de la cizaña (Mt 13, 24-30) y la de

78. The Five Gospels,5s.

79. Entre el libro de The Parables y el de Five Gospels hay algunas variaciones que no modifican estos tantos por ciento. Los cambios que hemos observado son éstos: la hoz y la cosecha de Tom 21,9 está impresa en negro en The Parables y en gris en The Five Gospels. La parábola del asesino de Tom 99, 1-3 está impresa en gris en The Parables y en rosa en The Five Gospels. Finalmente Mt 25, 29 está en negro en The Parables y en gris en The Five Gospels.

80. Es comprensible que las rechacen dada su opinión contraria a un Jesús que hable de escatología. Hablaremos de este aspecto más adelante.

81. Esta ha sido siempre una parábola discutida debido a que existen narraciones folklóricas anteriores. 
la red (Mt 13, 47-48)82 (frecuentemente considerada como secundarias porque reflejan la situación de la iglesia) y finalmente las parábolas del edificador de la torre (Lc 14,28-30) y la del rey que va a la guerra (Lc 14,31.32) ${ }^{83}$.

$\mathrm{El}$ Jesus Seminar en este tema no presentan un punto de vista radical. $\mathrm{Su}$ opinión es asumible.

\subsubsection{Criterios de autenticidad}

No todos los Evangelistas resultan igualmente favorecidos en la calificación que reciben sus aportaciones. El cuadro es el siguiente:

$\begin{array}{lll}\text { Mc: } & 0 \text { rojas; } & 3 \text { rosas } \\ \text { Mt: } & 2 \text { rojas; } & 7 \text { rosas } \\ \text { Lc: } & 3 \text { rojas; } & 10 \text { rosas } \\ \text { Tom: } & 1 \text { roja; } & 9 \text { rosas }^{84}\end{array}$

Considerando la aportación propia de cada uno, el cuadro es este otro:

Mc: 0 propias.

Mt: 2 propias, una en rojo y otra en rosa.

Lc: 7 propias, 2 de color rojo y 5 de color rosa.

Tom: 3 propias, una en color rojo y 2 en color rosa.

El cuadro se completaría diciendo que $Q$ tendría 2 rojas y 3 rosas.

Con estos datos podremos extraer esta conclusión: Juega poco papel el criterio de atestación en múltiples fuentes independientes. De las 22 parábolas en color rojo y rosa, 12 son propias de una sola fuente, es decir, más de la mitad.

Esta conclusión es normal. Frecuentemente se ha observado que las parábolas en su mayoría sólo están atestiguadas por una fuente. Si al criterio de múltiples fuentes independientes se le da un valor decisivo, la autenticidad de las parábolas quedaría malparada85.

Entonces, ¿cuáles son los criterios que aducen los "Fellows" para decidirse por la autenticidad o no de las parábolas?

82. El caso de estas dos parábolas es singular. Ambas se hallan solamente en Mt, no en Lc, por lo que no deben atribuirse a la fuente Q. Frecuentemente se consideran redaccionales de Mt. Curiosamente se hallan en Tomás (57 y 8). ¿Cómo explicar esta presencia? ¿Tomás depende de Mt? Así piensa la mayoría.

83. Hemos dicho que no reciben ni un sólo voto rojo; la razón hay que buscarla en la ya expuesta teoría sobre las parábolas como metáfora. Toda parábola debe tener algo extraño, chocante, que se salga de lo común. En estas dos parábolas todo es previsible.

84. Contamos la parábola del asesino (Tom 98) en rosa en The Five Gospels, aunque en la obra anterior la habían considerado gris.

85. Cfr. G. THEISSEN- A. MERZ, Der historische Jesus, 303-304. 
Continuamente es citado el criterio de que la parábola; por ser metáfora, tiene que presentar algo extravagante, chocante y sorprendente. Remitimos a lo dicho anteriormente sobre la teoría de las parábolas.

De este modo la parábola de la levadura es considerada como auténtica dado que para los judíos era algo impuro. Por lo que choca que Jesús se sirva de ella para ilustrar el reino de Dios. Igualmente es provocador y exagerado que Jesús proponga a un samaritano como héroe, o que el amo de la viña vaya repetidas veces a la plaza a buscar obreros y que al final pague el mismo jornal incluso a los que han trabajado poco. Extraña que el grano de mostaza, dada su pequeñez, se compare con el reino de Dios, al igual que se proponga como semejante a un cántaro vacío (Tom 97). La parábola del siervo cruel adolece también de rarezas y exageraciones.

El aspecto extravagante se nota más en estas parábolas. Jesús compara el reino de Dios con la manera de actuar de un administrador injusto y ladrón, o con un juez inicuo y malvado, o con el hombre de la parábola del tesoro que engaña al amo del campo, o con un asesino (Tom 98) que prueba el arma antes. En todos estos casos se proponen conductas moralmente dudosas y chocantes.

Muchas de estas observaciones son plausibles. No obstante, como hemos dicho anteriormente, la teoría de las parábolas que propugnan les obliga a ver cosas raras donde no las hay. Citamos a su tiempo varios casos.

Otras veces no ven extravagancias porque quizá ya tienen sentenciadas las parábolas como inauténticas por otros motivos. Un caso claro es la parábola de la cizaña. Esta parábola está llena de extravagancias. La cizaña se distingue del trigo fácilmente. Los obreros preguntan al amo cosas inútiles: si ha sembrado buena semilla en el campo. El enemigo, en vez de trabajar sembrando la cizaña, podía esperar a que el trigo estuviera maduro y prenderle fuego. Es raro también que se les mande a los obreros recoger primero la cizaña y luego el trigo. Lo normal sería hacer las cosas al revés ${ }^{86}$.

Otro ejemplo semejante sería el de la parábola de las vírgenes necias. Es extravagante que las vírgenes que van a velar tomen las lámparas y se olviden del aceite, que las amigas no les presten algo, que el novio les cierre la puerta por una insignificancia.

Quizá se diga que estas extravangancias se deben a que la parábola se ha alegorizado. Es perfectamente posible e incluso probable en los ejemplos citados. Pero el amo de la viña que paga el jornal íntegro a los trabajadores de la última hora, ¿no podía ser también un rasgo alegórico?

86. U. LUZ, Das Evangelium nach Matthäus (EKK I/1). II. Zürich-Neukirchen-Vluyn, 1990,324 enumera varias extravagancias. 
Nos parece, pues, que el criterio adoptado no es tan seguro como parece.

Por otra parte consideran que las parábolas del edificador de la torre (Lc 14,28-30) y del rey que va a la guerra (Lc 14,31-32) son inauténticas, porque en ellas no hay nada imprevisto e inesperado, todo sucede normalmente. Los protagonistas se dejan conducir por la prudencia humana. Ahora bien, el asesino de la parábola de Tom 98 también se porta normalmente, se limita a probar su arma antes de atacar. Esta parábola tiene el mismo sentido que la dos anteriores. Por mi parte tampoco encuentro nada raro en la parábola de los talentos. Todo sucede según lo esperado: se premia al laborioso y se castiga al vago. Pues bien, esta parábola es considerada por el Jesus Seminar como auténtica, al igual que la del asesino.

Otro criterio ampliamente usado es el de la brevedad, la ausencia de palabras superfluas. Y efectivamente esta brevedad se da en la parábola de la levadura, en la del tesoro oculto en el campo, en la de la perla, etc. El argumento invocado es que la tradición oral las conserva mejor. Pero tampoco este criterio se debe usar mecánicamente. Evidentemente esta brevedad no se da en la parábola del hijo pródigo, ni en la de los trabajadores de la viña, ni en la del siervo cruel, ni en la de los invitados al banquete.

Por contra, extraña que se considere como rosa la parábola del fariseo y del publicano, aunque se reconoce que refleja la rivalidad entre cristianos y judíos y sólamente se halla en Lc.

En cuanto a la autenticidad de las parábolas, a pesar de la debilidad de los criterios, puede decirse que fundamentalmente su opinión es aceptable. Habría que ver ulteriormente cómo son interpretadas por ellos: si van unidas al reino de Dios y qué clase de reino de Dios ilustran. Pero esta labor no la hacen en sus obras publicadas hasta ahora.

\subsubsection{The Five Gospels}

Este libro tiene la ventaja de presentar la versión en inglés de los cinco evangelios en color por secciones, acompañada de las razones por las que los "Fellows" han tomado ésta o aquella postura. Estos comentarios son más extensos en este libro que en el The Parables; son más largos cuando las palabras son discutidas y el consenso es menor.

Nos limitaremos a las palabras de Jesús que no son parábolas. La primera impresión que el lector tiene al pasar las páginas es de desolación. Existen páginas enteras sin que aparezca una breve frase en color rojo o rosa. En Marcos, por ejemplo, si exceptuamos las parábolas en rosa, solamente se hallan unos 15 aforismos en color rosa. Abunda, en cambio, el color negro. 
Mi opinión es que encontramos cosas razonables, otras, discutidas y finalmente bastantes, inaceptables.

\subsubsection{Los “Fellows" no están sólos}

El término preferido por los miembros del Seminario es el de aforismos para designar a los dichos de Jesús que no son parábolas. Aunque a veces hablan de cuatro categorías del material evangélico: aforismos, parábolas, diálogos e historias (pronouncement stories), prácticamente las palabras de Jesús se reducen básicamente a estas dos categorías: parábolas y aforismos. Las historias, que son fundamentalmente los apotegmas de Bultmann, contienen un dicho de Jesús que es lo importante. La breve narración en la que está incrustado el dicho no tiene mayor interés. Los diálogos, por su parte, a parte de ser escasos en la tradición sinóptica, se reducen también a palabras y sentencias breves.

No todas las palabras de Jesús son aforismos. Los dichos de Jesús breves existentes en los relatos de milagros, por ejemplo, no lo son. Pero también son juzgados por los "Fellows". En los relatos de milagros, Jesús suele decir alguna frase:" quiero, queda limpio", "levántate y vete a casa", "extiende la mano", "vete, tu fe te ha salvado" (Mc 10,52) etc. En los exorcismos suele hallarse la frase "cállate y sal de él", o parecidas. Pues bien, todas estas frases se ponen en color negro. Los argumentos son siempre los mismos: son palabras sacadas de la historia, forman parte de ellas; no han existido sólas en la tradición, no son independientes de la narración, etc. Por ello son creaciones del narrador.

Esta opinión es razonable. No tiene ni tuvo entonces ningún interés saber si Jesús a un ciego le tocó los ojos o le dijo "ve", si le mandó a otro extender la mano o meramente se lo indicó. Es sabido que las narraciones de milagros están formalizadas, llenas de tópicos, de unidades linguísticas hechas, que no permiten alcanzar el suceso concreto. La única pregunta que debe hacerse en estos casos es si Jesús hizo estos hechos. Pero el Jesus Seminar metodológicamente prescindió en esta publicación del estudio de los hechos de Jesús.

Los aforismos o apotegmas son más interesantes. Se trata de sentencias memorables, propias de una personalidad con carisma, dicen algo importante y digno de recordarse. En el judaísmo antes de Cristo no se usó este género literario; sus paralelos más próximos son los apotegmas o Chreiai helenistas. Suelen distinguirse apotegmas biográficos de un lado y apotegmas de enseñanza y controversia de otro. Los primeros se hallan, por ejemplo, en los relatos de vocación de los discípulos, en los que Jesús dice: “Sígueme, os haré 
pescadores de hombres"(Mc 1,17) o simplemente "sígueme" (Mc 2,14). Estos apotegmas son impresos en color negro o gris. Consideran que no han podido transmitirse independientemente de la narración que ahora les acoge. Los creen, como Bultmann, escenas ideales.

Distinta es la suerte de los apotegmas de controversia y enseñanza que en Mc se encuentran en tres series: Mc 2,1-3-6; 10,1-45 y 12 13,44. Mayoritariamente los imprimen en color rosa. Tales son los aforismos como "no necesitan médicos los sanos sino los enfermos" (Mc 2,17), la frase sobre el ayuno (Mc $2,19)$, el dicho sobre el vino nuevo en odres viejos (2,22), la sentencia de Jesús sobre el sábado (Mc 2,27), las frases sobre el impedimento que representa la riqueza para entrar en el reino (Mc 20,23.25), etc.

Felicitamos en este aparatado a los miembros del Jesus Seminar por reconocer como rosa el dicho de Jesús sobre la impureza ritual: "no contamina lo que entra, sino lo que sale del hombre"(Mc 7,15; Mt 15,10-11; Tom 14,5). Se apartan así de la postura dogmática y sorprendente de E. P. Sanders que negaba la autenticidad porque le parecía muy revolucionario ${ }^{87}$.

\subsubsection{Los "Fellows" se quedan más solos}

Señalemos brevemente algunos textos que sólo ellos o una franca minoría señala como problemáticos o inauténticos.

Causa extrañeza que consideren como gris o como negro el dicho de Jesús sobre el divorcio. Reconocen que hay razones gravísimas para suponer su autenticidad: está documentado el "logion" en más de dos fuentes independientes (Mc, Q y Pablo); esta prohibición creó dificultades, como se ve por las excepciones de Mt y Pablo; el aforismo cumple todas las reglas que ellos asignan a los originales de Jesús y finalmente va contra las convenciones sociales y religiosas.

Ante estas razones valen poco las aducidas por ellos contra la autenticidad: que la fórmulas varían, que los textos se han adaptado a situaciones eclesiales, o que Mc refleja el derecho matrimonial romano, punto éste último no cierto ${ }^{88}$. La debilidad de las razones es manifiesta, pues no ésta, sino todas las palabras de Jesús se hallan adaptadas.

Creo que les ocurre aquí lo que les pasa con el carácter presente y futuro del reino de Dios: consideran incompatibles ambas ideas. En el caso que tra-

87. Jewish Law from Jesus to Mishnah. Five Studies. London-Philadelphia, 1990, 28.

88. También en el ambiente judío y oriental la mujer podía tomar la iniciativa del divorcio. Recoge los testimonios M. FANDE, Die Stellung der Frau im Markusevangelium. Münster 1989,200-257. 
tamos, Jesús habla del amor incesante de Dios al hombre y a la mujer y, de otra parte, postula sin condiciones la indisolubilidad del matrimonio. Ambas cosas se dan en Jesús. ¿Son contradictorias? Lo que debe hacer el investigador es costatarlo, si ve razonable que los dos puntos son seguros.

También se manifiestan contrarios a la autenticidad de las antítesis de Mt, y ello, a pesar de que consideradas con atención encontrarían en ellas algunas características favorables a la autenticidad: En ellas Jesús va en contra de las convenciones sociales y religiosas y, además, hay exageraciones e hipérboles. Negando la autenticidad en bloque, se distancian de la opinión común que suele admitir como auténticas la primera, la segunda y, quizá, la cuarta, es decir, las antítesis sobre el asesinato, el adulterio y el juramento ${ }^{89}$. Son las tres que radicalizan la Tora, y no hay paralelos en forma no antitética.

Imprimen con excesiva decisión en color negro los condenas dirigidas contra las ciudades en torno al lago, Corozain y Betsaida (Mt 11,21-24; Lc 10,13-15). Antes que ellos ya Bultmann se los atribuía a un profeta cristiano. La razón que dan es la siguiente: creen imposible que Jesús, que ha mandado a los discípulos amar a los enemigos, condene al infierno a los que le rechazan a El. Si embargo, hay graves razones para admitir como auténticos los vv. 21-13 de Mateo y así se suele hacer ordinariamente90. Corozain no es citada en el resto del N. T.; en época antigua no consta que en Tiro y Sidón hubiera comunidades cristianas; estos versillos no dicen mucho más que Lc 11,31s y 13, 28 con los que están relacionados en cuanto al contenido; el ¡ay! no es una maldición sino una amenaza. Con todo, se comprende bien la postura del Jesus Seminar contraria a la autenticidad. El dicho de Jesús supone el juicio final y ellos no quieren oír hablar de un futuro escatológico.

\subsubsection{Opiniones inaceptables}

El punto ciertamente más negativo es la eliminación de todo dicho de Jesús que hable del reino de Dios en perspectiva futura y escatológica por creerlo incompatible con el reino de Dios como presente que aparece en otros textos. Como solución general han adoptado poner en negro todos los dichos de Jesús que hablen del reino como futuro91.

89. U. LUZ, El Evangelio según san Mateo. Salamanca 1993, 343-344; J. GNILKA, Das Matthäusevangelium. Freiburg 1986, II, 152-158. I, 430 .

90. U. LUZ, Das Evangelium nach Matthäus, II, 192; J. GNILKA, Das Matthäusevangelium,

91. The Five Gospels, 137. 
Quizá por benevolencia ponen en gris esta frase de Mc 14, 25: "Os aseguro que ya no beberé más del producto de la vid hasta el día aquel en que lo beba nuevo en el reino de Dios". El texto se halla también en Mt y Lc; estos dos son impresos en negro, sin saber por qué, puesto que se trata del mismo versículo. Este dicho tiene todas las garantías de remontar a Jesús. Aquí Jesús no habla como un cristiano, no se identifica con el reino de Dios, se expresa como un piadoso israelita que espera el reino de Dios. El no es el centro de la esperanza sino el reino. Conocedor de que va a morir próximamente, espera más allá de la muerte alcanzar el reino que indudablemente llegará.

También colocan en negro Lc 13, 28-29 y el paralelo de Mt 13,11-12: "Vendrán muchos de oriente y de occidente y se pondrán a la mesa en el reino de los cielos, mientras que los hijos del reino serán echados fuera". El logion recoge el tema de la peregrinación de los pueblos hacia Sión (Isa 2,2s.; Miq $41,1 \mathrm{~s}$ ) y del banquete escatológico (Isa 25,6) y lo dirige contra Israel: admisión de paganos y exclusión de Israel. Y esto sucederá en el futuro escatológico, más allá de la muerte, pues asisten los patriarcas. Así no habla la comunidad cristiana que espera la entrada de los paganos en la iglesia ya ahora en el tiempo presente92. Además la marcha de los paganos en el A. T. es centrípeta, hacia Jerusalén y Sión, y no centrífuga y misionera como en la comunidad cristiana.

También imprimen en negro o en gris las llamadas "palabras de entrada en el reino o en la vida", como por ejemplo, Mc 9,43-45 que habla de cortar la mano o el pie o perder el ojo con tal de entrar en la vida. La extrema radicalidad del dicho habla a favor de su autenticidad. Notable es entre estos dichos el de Mt 21,31b: "En verdad os digo que los publicanos y las rameras os precederán en el reino de Dios". El 53 \% de los "Fellows" votaron rojo o rosa, es decir la mayoría, pero se imprime in gris por el gran número de bolas negras. El contraste y la radicalidad es semejante a la que hay para Jesús entre el rico y el pobre; éste entra, el otro, no. Se hace difícil negar la originalidad de este dicho ${ }^{93}$.

Finalmente citemos dos textos que los "Fellows" consideran auténticos, pero que los entienden inexplicablemente como referidos al reino de Dios presente. El primer caso es el de la segunda petición del Padre Nuestro. La traducen así: Impose your imperial rule. Dejamos a los angloparlantes juzgar si esta traducción imperativa es más correcta que la usual Your Kingdom come en forma de deseo. Consideran que Mt interpreta esta petición median-

92. Remonta a Jesús según U. LUZ, Das Evangelium nach Matthäus. II, 14 y J. GNILKA, Das Matthäusevangelium. I, 305.

93. "...einem Logion, das wegen seines umstürzlerischen Inhaltes fast einhellig als autentisches Jesuswort angesehen wird": J. GNILKA, Das Matthäusevangelium II, 223. 
te la siguiente. Pero de cualquier manera que se traduzca, la interpretación escatológica es indiscutible ${ }^{94}$. Que se implore que el reino de Dios venga supone su no presencia actual y por tanto su dimensión futura. En las oraciones judías se pide la venida del reino de Dios, a pesar de que los Rabinos hablan frecuentemente de la dimensión presente del reino ${ }^{95}$.

Lo mismo se puede decir de las Bienaventuranzas. Los "Fellows" colocan las tres primitivas en color rosa en la versión de Mt y en color rojo en la de Lc. Ahora bien, las bienaventuranzas son ininteligibles sin un cambio total de las circunstancias presentes. La experiencia diaria del no tener, sufrir y no quedar saciados desmiente la felicidad ya presente.

La eliminación de la escatología del Jesús histórico nos parece comparable a lo que quiso hacer la vieja teología liberal eliminando la tradición de los milagros. Tal reducción resultó imposible de hacer, dada la presencia de la tradición en todas las fuentes y la tradición milagrera en los ámbitos judío y helenista de entonces. Por lo demás, el Evangelio de Tomás pone en boca de los discípulos la doctrina escatológica del reino, a la que Jesús responde corrigiéndola (Tom 51). Este dicho presupone la existencia de esa doctrina en el cristianismo que se elimina por las ideas gnósticas.

\subsubsection{Imagen de Jesús en el Jesus Seminar}

El Jesus Seminar como tal no ha escrito un ensayo sobre el Jesús histórico. Tampoco, que se sepa, ha publicado un libro oficial sobre los hechos de Jesús en cuya tarea, al parecer, está actualmente trabajando. Un anticipo de esta labor podría ser el de W. BARNES TATUM, John the Baptist and Jesus. $A$ Report of the Jesus Seminar ${ }^{6}$. En él se estudia todo lo referente a Juan Bautista, también sus hechos, tiempo, lugar, discipulado, etc.

Por ello no es sencillo exponer la imagen que el Jesus Seminar tiene. Puede, no obstante, colegirse de lo que piensan sobre las fuentes históricas más fiables de Jesús, de los criterios de historicidad que usan, de las declaraciones y publicaciones de sus miembros, algunos de los cuales han escrito ya ensayos sobre Jesús, etc.

A nuestro juicio el punto básico sobre el que se funda su presentación de Jesús es el tandem $Q+$ Tomás supuesto por ellos.

Recordemos que tienen un gran aprecio a Q; la descomposición de esta fuente en estratos y la clasificación de la capa más antigua (Q1) con conteni-

94. U. LUZ, El Evangelio según San Mateo, II, 478-479: "Es indudable el elemento escatológico de esta petición"(p. 479).

95. Textos en STRACK- BILLERBECK. I, 418s.

96. Sonoma 1994. 
dos exclusivamente sapienciales es una especie de dogma para ellos. Al mismo tiempo atribuyen un alta antigüedad al Evangelio de Tomás, que no tiene nada de escatológico o apocalíptico. De este modo se consolidan dos fuentes, antiguas e independientes que coinciden en presentar un Jesús predicador de una doctrina sapiencial. Los temas escatológicos, entre ellos la designación de Jesús como hijo del hombre, el reino de Dios como futuro, son una excrecencia de la tradición.

El cuadro se completa observando cómo para ellos detrás de Q1 hay una comunidad cristiana que prescinde de todo lo que no tiene el documento con el que se identifica. De esta manera sobre la base de un texto hipotético (Q1), hecho sobre un texto ya hipotético $(\mathrm{Q})$, se adivina hipotéticamente un primer grupo de cristianos que se habría contentado solamente con el mensaje sapiencial, sin futuro y sin soteriología unida a la muerte y resurrección, debido a que Q carece de relato de la Pasión. El verdadero Jesús sería un sabio contestario, a la manera de un Sócrates o un filósofo cínico que ofrecía a sus seguidores consejos de filosofía práctica. No tenía ningún lazo de unión con la tradición profética y no participaba de las esperanzas mesiánicas y escatológicas, aislado del pueblo y de la Escritura. El judaísmo y la ideas judías no revestían importancia alguna. Su objetivo y sus ideas eran otras: una filosofía del talante de los cínicos helenistas. Sus seguidores la recogieron como los discípulos de Sócrates recogieron la doctrina del maestro ${ }^{97}$.

Los cristianos de Q pensarían poco más o menos así: Jesús está presente en la palabra; la fe en esta palabra le hace presente y real. Sólo aquí en la palabra el reino de Dios está presente. El fin ha llegado ya en la enseñanza de Jesús. Es una escatología vertical, no horizontal98. De esta manera se

97. Los más conocidos partidarios de la hipótesis cínica son J. D. Crossan, B. L. Mack, L. Vaage y R. Cameron, todos ellos Fellows del "Jesus Seminar". A ellos hay que añadir el inglés G. Downing que desde otros supuestos ya desde 1982 viene insistiendo en la misma tesis. De J. D. CROSSAN dos de sus obras están traducidas al castellano: Jesús, vida de un campesino judío. Barcelona 1994; Jesús: Biografía revolucionaria. Barcelona 1996. Crossan presenta un Jesús cínico judío, pero un tanto diluido. El hecho de que sólo lo diga al final de su obra y de pasada manifiesta que no le da excesiva importancia. Por el contrario, B. L. MACK presenta a Jesús como filósofo cínico, helenizado, urbano, cosmopolita y librepensador. Cfr. B. L. MACK, A Myth of Innocence. Mark and Christian Origins. Minneapolis 1988; ID. The Lost Gospel. The Book of $Q$ and Christian origins. San Francisco 1993 (traducida al castellano, El Evangelio perdido. El Documento Q. Barcelona 1993); L. VAAGE, Galilean Upstarts: Jesus' First Followers According to $Q$. Valley Forge 1994; R. CAMERON, "What have you Come Out to See?: Caracterizations of John and Jesus in The Gospels": Semeia 19(1990); de G. DOWNING la obra más completa sobre el tema es Christ and the Cynics:Jesus and other Radical Preachers in First-Century Tradition. Sheffield 1988.

98. N. T. WRIGHT, The New Testament and the People of God (Christian Origins and the Question of God, 1). Minneapolis 1992, 437. 
puede recuperar el "mito de la inocencia" 99 antes de que las narraciones de Hechos y de los Evangelios fabricasen el mito cristiano.

La sabiduría de Jesús fue provocativa, retadora, superaba el sentido común de la sabiduría popular desde una vivencia de la presencia de Dios. Esta sabiduría presenta una manera de vivir social alternativa basada en la compasión, eliminando las barreras sociales, como se pone de manifiesto en la práctica de las comidas abiertas. Este reinado de Dios presente, no patriarcal, sin intermediarios, abarca maneras de pensar ascéticas, libertarias, anarquistas, cínicas, etc. 100. El reino de Dios es, de este modo, un estilo de vida, que permite a todos acceder a la compañía y a la sabiduría sin la mediación del status social. Muchos han visto aquí el ethos del profesor burgués del s. $\mathrm{XX}$ : un hombre que se expresa verbal y prácticamente de un modo políticamente correcto y socialmente aceptable.

Las reparos y objeciones a esta cascada de hipótesis son muchas y variadas.

\section{Con referencia a la fuente $Q$}

Como hemos visto, afirman que Q1 es un estrato sapiencial; en la siguiente edición el documento se cargó con material profético y apocalíptico. Prescindiendo del carácter hipotético de esta división ${ }^{101}$, nos queremos fijar en esa contraposición que se hace entre sapiencial y profético.

Kloppenborg mismo reconoce que dichos singulares a veces son ambiguos y pueden aparecer sapienciales o proféticos. Entonces hay que acudir al carácter de la obra. Y Q se presenta en forma de "dichos de los sabios".

Koester se separa de Kloppenborg. Para él sapiencial y apocalíptico son incompatibles, aunque no sapiencial y escatológico. El discurso inaugural de 6, 20-49102, siendo un discurso sapiencial, es también profético y escatológico; es anuncio de la futura presencia del reino de Dios, pero no es apocalíptico, pues no anuncia el juicio y la condena. Koester entiende que el primer estrato de $\mathrm{Q}$ es sapiencial y escatológico a la vez ${ }^{103}$. Los dos, pues, convienen en calificar de sapiencial el primer estrato.

99. B. L. MACK, A Myth of Innocence. Mark and Christian Origins. Philadelphia 1988;ID., El Evangelio perdido. El Documento Q. Barcelona 1993.

100. A esta imagen llega J. D. CROSSAN, Jesús: Vida de un Campesino Judio. Barcelona 1994, 285. Si el Jesus Seminar algún día escribe un ensayo sobre Jesús no se diferenciará mucho del presentado por Crossan.

101. N. T. WRIGHT, The New Testament and the People of God, 439, nota 72, enumera algunas de las petitio principii en la obra de Kloppenborg.

102. Es usual citar la fuente $Q$ según la versión de Lc. Los versículos citados comprenden las bienaventuranzas que sería el comienzo del supuesto estrato de Q1.

103. H. KOESTER, Ancient Christian Gospels, 137-138; 156-157. 
Pero esta no es la opinión común. Hay quien sin negar el aspecto sapiencial de $Q$, no ve razón alguna para presentar al sabio y al profeta como incompatibles. Otros, en fin, como Sato, resaltan, por el contrario, el carácter profético de $\mathrm{Q}^{104}$.

Dejando a un lado esta diferencia de opiniones, digamos simplemente que si se acepta la definición de la sabiduría de G. von Rad como "un conocimiento práctico ...basado en la experiencia"105, es difícil considerar las bienaventuranzas como sapienciales. Así no habla un sabio. Igualmente debe decirse de las exhortaciones sobre el no andar preocupado por el alimento y el vestido (Lc 12,22-31). Hay que recordar que se recomienda no trabajar ni preocuparse del futuro. Todo lo contario aconsejaban los sabios. Las exigencias de la vocación (9,57-61) y la instruciones a los discípulos enviados a misionar (Lc 10,1-8) tampoco son sapienciales, son normas de conducta dirigidos a personas en una situación concreta.

Por tanto no se niega la existencia de elementos sapienciales, pero han sido recogidos por una fuerte tradición escatológica y profética ya en el primer estrato, si es que existió como tal106. Tal combinación de tradición sapiencial y discurso prófetico es totalmente natural en la Palestina de entonces ${ }^{107 .}$ Precisamente es $Q$ la que afirma que Jesús es más que Salomón y más que Jonás (Lc 11,31-13, es decir, es más que los sabios y profetas.

Resulta difícil distinguir el nivel sapiencial y el nivel apocalíptico porque la literatura apocalíptica ha sido producida por sabios108. "Sólo los sabios comprenden" lo que está por venir (la escatología) (Dan 12,10).

Además tenemos el ejemplo de Qumran. N. T. Wright ${ }^{109}$ cita la Regla de la Comunidad. Este escrito manifiesta claramente que la comunidad cree vivir ya en la "alianza de la gracia" $(1,7.16)$, es decir, profesa una especie de escatología realizada. Resulta que poco más adelante se espera un futuro para la comunidad: los Mesías de Israel y de Aarón $(9,11)$ y el día de la venganza $(9,23)$. De otra parte en Qumran abundan los textos sapienciales ${ }^{110}$ y nadie puede negar la mentalidad escatológica de la secta.

104. M. SATO, $Q$ und Prophetie. Studien zur Gattungs- und Traditionsgeschiche der Quelle Q.(WUNT 29). Tübingen 1988.

105. Teología del A. T. Salamanca 1972, I, 508.

106. CH. M. TUCKETT, $Q$ and the History of Early Christianity. Studies in $Q$. Peabody 1996, 139-163.

107. N. T. WRIGHT, The New Testament and the People of God, 439.

108. R. HORSLEY "Wisdom justified by all Her Children. Examining Allegedly Disparate Traditions in Q": E. L. LOVERING(ed.) SBL. Seminar Papers. Atlanta, 1994, 733751, espec. $735-736$.

109. N. T. WRIGHT, The New Testament and the People of God, 439-440.

110. Sobre ellos puede verse D. J. HARRINGTON, Wisdom Texts from Qumran. Routledege 1996. Un capítulo entero del libro está dedicado a 4QSapiential A, el más exten- 
Con referencia al Evangelio de Tomás.

Tampoco puede pensarse que Tomás refleje un cristianismo inocente, intacto y original.

Tomás tiene dichos acerca del reino de Dios, o como dice el evangelio ordinariamente, el reino del padre. Su significado parece claro: es el conocimiento actual y secreto que el gnóstico tiene del mundo celestial. ¿De donde procede este significado del reino de Dios? Es claro que proviene del mundo judío. Esta expresión "Reino de Dios" en el curso del tiempo se ha ido cargando de significados diversos: restauración de Israel, reedificación del templo, el esplendor de Sion, venida de las naciones a Jerusalén, liberación de los romanos, purificación del templo, etc. Todo ello según las necesidades del momento y según la mentalidad de los diversos círculos del judaísmo. Es por tanto seguro que la idea del reino que el evangelio de Tomás tiene, es una evolución tardía hacia un sentido individual y gnóstico, alejándose de este modo del sentido comunitario y nacional anterior. La evolución inversa es impensable.

Hoy por hoy lo más seguro es que círculos del cristianismo primitivo representados por el Evangelio de Tomás se fueron separando de unos puntos de vista judíos apocalípticos y derivando hacia una interpretación no escatológica del mensaje cristiano. Un ejemplo parecido sería el evangelio de Juan, que en el curso de su composición pasó por diversas redacciones sufriendo "una transformación de la tradición escatológica 'futurista'(espera de la salvación futura) en una dimensión 'presentista"(salvación ya presente)"111; en una etapa ulterior recibió influencia de la gran iglesia.

La eliminación de la escatología del mensaje de Jesús.

Este es el elemento, sin duda, más rupturista con la investigación llevada hasta ahora. Había y creo que hay fuera del círculo del Jesus Seminar un consenso generalizado que Jesús habló del Hijo del hombre y del reino como futuro, una nueva era provocada por la acción divina que traería las realidades escatológicas: resurrección y nueva vida. Este reino ya estaba presente, por otra parte, en él ocultamente, pues no es un lugar ni un estado, sino una realidad dinámica que es posible apreciarlo allí donde surgen espacios de libertad y de

so texto sapiencial hasta ahora inédito de la cueva 4. Se han encontrado 6 copias del escrito. 111. S. VIDAL, Los Escritos originales de la Comunidad del Discípulo "Amigo" de Jesús. El Evangelio y las cartas de Juan. Salamanca 1997, 29. 
vida, donde se elimina el mal. Desde fines del s XIX por mérito de Weiss y Schweitzer esta opinión se impuso de una manera prácticamente unánime.

Para Schweitzer el Jesús escatológico y apocalíptico sería en nuestro tiempo un "extraño y desconocido"; no obstante, su escatología es una óptima motivación ética que nos impulsa a la transformación del mundo.

El Jesus Seminar rompe el nudo gordiano, elimina la "extrañeza" de Jesús suprimiendo uno de los datos seguros. Ya hemos indicado que los textos que hablan del reino de Dios son varios y es imposible atribuir su origen a la comunidad. Ellos, por contra, consideran que liberar a la investigación del Jesús escatológico en el que está envuelto el tema desde Weiss, es la base de la nueva era que ellos representan ${ }^{112}$. La supresión de la escatología ya la anunciaban desde 1985, año de la fundación del Seminario, porque resultaba molesta para la mentalidad moderna, como hemos visto anteriormente. Ahora bien "lo que es inconveniente para los intereses modernos no debe ser barrido de las fuentes antiguas" 113 .

La eliminación de estos textos es importante no por su cantidad, sino por su calidad. La imagen de Jesús cambia muchísimo. El Jesús se seculariza enormemente. No parece ya interesado por el porvenir del pueblo de Israel, ni por su religión. En verdad quitan a Jesús su carácter judío y se le convierte en predicador laico de una contracultura o en una especie de abogado de los pobres a la antigua usanza.

Esta opinión se enfrenta a hechos imposibles de explicar. Es un hecho que Jesús murió en la cruz. Ahora bien es difícil entender que un predicador campesino, o si se quiere urbano, con un programa tan blando y utópico, pueda haber parecido como peligroso a los romanos. La muerte violenta supone evidentemente que Jesus provocó odios y enemistades, molestó a muchos, concretamente a las autoridades. Un Jesús edulcorado sin una crítica acerva a las autoridades y a los intereses de las clases pudientes no es el Jesús de la historia.

En segundo lugar la eliminación del Jesús escatológico presenta una historia de las ideas realmente sorprendente. Reconocen que Juan Bautista fue un profeta escatológico ${ }^{114}$. También lo fue la primitiva comunidad cristiana.

112. The Five Gospels, 4.

113. B. CHILTON, Pure Kingdom. Jesus' Vision of God. Grand Rapids, 1996, 9.

114. W. BARNES TATUM, John the Baptist. A Report of the Jesus Seminar, Sonoma, 1994, p. 141. Se da aquí el dato siguiente: la proposición de si Juan Bautista fue un predicador apocalíptico, mereció el color rosa. No obstante algunos miembros del Jesus Seminar se han manifestado en contra del carácter apocalíptico de este personaje. Cfr. R. CAMERON, "What Have You Come Out to See?: Characterizations of John and Jesus in the Gospels": Semeia 49(1990)39-69, especialmente 62. 
Pero Jesús, discípulo del primero y maestro de la segunda, no lo fue. Esto cuesta creerlo115.

Quizá lo más irritante sea el papel que atribuyen a la investigación histórica, naturalmente la suya ${ }^{116}$. Implícitamente o explícitamente entienden que el conocimiento histórico es normativo para la fe y, por tanto, para la teología. El más claro es J. D. Crosssan: "Si no se puede creer en una cosa que es fruto de la reconstrucción, quizá no quede nada en lo que creer"117. Esta frase le hace decir a J. Neusner que Crossan se manifiesta "with surpassing eloquence (but little humility)"118. Crossan exige la fe en su reconstrucción. Esto es ir más allá de la tarea de historiador.

Pretenden reformar el credo cristiano, pues la historia determina la fe. Esto es lo que indicaría esta frase atrevida: "El Cristo del credo y del dogma, que estaba firmemente anclado en su lugar en la Edad Media, no puede por más tiempo exigir el asentimiento de aquellos que han visto los cielos a través del telescopio de Galileo"119. Esta otra es también significativa: El credo Niceno "sofocó el Jesús histórico". El credo proviene de la "influencia de Pablo, que no conoció al Jesús histórico y para quien el hombre Jesús no jugó ningún papel"120.

Hace años se dijo que Bultmann no debía ser tomado en serio ${ }^{121}$. Algo parecido se está diciendo ahora del Jesus Seminar122. Ha resultado fatal compartimentar y estudiar por separado dichos y hechos de Jesús. Sobre la base de un puñado de palabras sueltas y aisladas de su vida difícilmente pueden hacerse afirmaciones sobre Jesús.

Recurrir, por otra parte, a una pretendida antigüedad de las fuentes hipotéticas y al mismo tiempo desechar al Apóstol Pablo, resulta problemático

115. Es sintomático que $\mathrm{H}$. Koester, inspirador de algunos puntos de vista del Jesus Seminar, no vea posible privar a Jesús de una escatología futura.("Jesus the Victim": Journal of Biblical Literature 111(1992)3-15.

116. L. T. JOHNSON, The Real Jesus: The Misguided Quest for the Historical Jesus and the Truth of the Traditional Gospels. San Francisco 1996, 55.

117. Jesús: Vida de un campesino judio, 488.

118. "Who Needs 'The Historical Jesus'? An Essay-Review": Bulletin for Biblical Research 4(1994),113-126, cit. en p. 115.

119. The Five Gopels, 2.

120. The Five Gospels, 7.

121. A. M. HUNTER, Introducing New Testament Theology. London 1957, 11.

122. "Der nicht eschatologische Jesus' scheint mehr kalifornisches als galiläisches Lokalkolorit zu haben", (G. THEISSEN-A. MERZ, Der Historische Jesus, 29). B. WITHERINGTON III afirma que la opinión que recogió por Europa fue "que el Jesus Seminar pertenece a ese tipo de cosas que sólo pasan en América" (The Jesus Quest. The Third Search for the Jew of Nazaret. Downers. Grove 1995, 260, nota 13). 
para la investigación. Los escritos de Pablo tiene mayor antigüedad y son documentos que se conservan y no hipotéticos.

El Jesus Seminar no es el único que descuida a Pablo. Este olvido del Apóstol incide en las presentaciones modernas de Jesús. En la Third Quest se rechaza con razón el criterio de discontinuidad con el judaísmo al menos en su formulación más dura. Se prefiere insertar a Jesús en el judaísmo, lo que está muy bien. Pero esta preferencia y la mala conciencia cristiana respecto del judaísmo provocan que se presente a Jesús como un judío fiel a la ley y a las instituciones básicas del judaísmo123. Ahora bien, si esto es así, ¿cómo se puede explicar que Pablo, apenas tres años después de la muerte de Cristo por celo por la ley persiga a los cristianos? (Gal 1,13).

No se puede esperar que todas las visiones de Jesús sean compatibles con la fe cristiana. Lo mismo que en su vida mortal también ahora despierta adhesiones, indiferencia y odios. Tampoco entre los cristianos las presentaciones de Jesús van a coincidir; a lo mejor no es deseable; de hecho tenemos cuatro evangelios. Pero al menos se esperaría que ningún historiador serio se erigiera en apóstol y canon de una nueva fe. La historia no da para tanto ni a favor ni en contra.

Beware of finding a Jesus entirely congenial to you= Precaverse frente a una imagen enteramente semejante a tí124, advierten los "Fellows" del Seminario. Es muy sano este consejo, también para ellos. Parece que los investigadores están condenados a esta subjetividad. Si los resultados son tan congeniales con quien escribe de Jesús, ¿por qué seguir en la tarea?. "¿Quién necesita al Jesús histórico?", se preguntaba J. Neusner ${ }^{125}$.

Las parcialidad o subjetividad de los resultados y estimaciones no son razón para desistir en el estudio. Todas las ciencias están sujetas a la misma subjetividad. Pero de la misma manera que en otros órdenes de saberes el tiempo se encarga de discernir el sensacionalismo de las investigaciones serias, también sucederá con nuestro tema. De hecho eso ha ocurrido en el pasado.

123. G. VERMES, Jesús el Judio. Los Evangelios leidos por un historiador. Barcelona 1977; ID., Jesus and the World of Judaism. London 1983; ID., La Religión de Jesús el Judio. Madrid 1996; E. P. SANDERS, Jesus and Judaism. London 1985, 245-269; también el Catecismo de la Iglesia Catolica presenta a Jesús como cumpliendo en su totalidad la ley y profesando el más profundo respeto al Templo (Nr. 577-586). Una crítica a esta manera de pensar y específicamente contra Sanders puede verse en M. HENGEL-R. DEINES, “E. P. Sanders' 'Common Judaism', Jesus and the Pharisees": The Journal of Theological Studies,46 (1995)1-70, espec.5-16.

124. The Five Gospels, 5.

125. "Who Needs 'The Historical Jesus'", 113-126. 
La siguiente frase de $\mathrm{K}$. Barth debiera hacer reflexionar a muchos componentes del Jesus Seminar: "Un cristianismo, que no es escatología en todos y cada una de sus componentes, no tiene absolutamente nada que ver con Cristo"126.

C. MIELGO.

126. Der Römerbrief. 1919.2 ed., 298. 